BIM AND COMMUNICATION: IMPLEMENTATION OF BUILDING INFORMATION MODELING INTO AN INTEGRATED PROJECT DELIVERY CONTRACT TO ENCOURAGE PROJECT

TEAMS TO COMMUNICATE

\author{
A Thesis \\ presented to \\ the Faculty of California Polytechnic State University, \\ San Luis Obispo
}

In Partial Fulfillment

of the Requirements for the Degree

Master of Science in Architecture

by

Kathleen Worden

June 2016 
(C) 2016

Kathleen Worden

ALL RIGHTS RESERVED 


\section{COMMITTEE MEMBERSHIP}

TITLE: BIM And Communication: Implementation Of Building

Information Modeling Into An Integrated Project Delivery

Contract To Encourage Project Teams To Communicate

AUTHOR: Kathleen Worden

DATE SUBMITTED: June 2016

COMMITTEE CHAIR: Elbert Speidel, M.Arch

Lecturer of Construction Management

COMMITTEE MEMBER: Margot McDonald, M.Arch

Department Head of Architecture

COMMITTEE MEMBER: John Lawson, M.S.

Associate Professor of Architectural Engineering 


\begin{abstract}
BIM And Communication: Implementation Of Building Information Modeling Into An Integrated Project Delivery Contract To Encourage Project Teams To Communicate
\end{abstract}

\title{
Kathleen Worden
}

The objective of this thesis is to explore BIM, IPD and their implementation into a building project contract. The Integrated Delivery Processes is comprised of a collaborative team of Designers, Constructors, and Owners working side by side to create a successful project. BIM has been introduced as a technology into the industry, as a tool that these parties can use for better understanding the project.

Through case studies of IPD projects using BIM are observed, it was determined that although BIM was used, one problem faced is the lack of BIM standards included initially in a contract for in an IPD project. There are templates available by the AIA, AGC, and USACE, but they are not all standalone documents. A guideline for the parities to discuss will be introduced as conversation piece that would help segue into what might be included in the contract documents. 


\section{ACKNOWLEDGMENTS}

I would first like to thank my thesis advisor Elbert Speidel of the School of Architecture at Cal Poly, San Luis Obispo. Professor Speidel was the one who introduced me to the subject of BIM during my undergraduate studies.

I would also like to thank the rest of my thesis committee Members Professors John Lawson and Margot McDonald of the School of Architecture at Cal Poly, San Luis Obispo. Their input and guidance, helped me discover what I truly wanted this thesis to be about.

I would also like to acknowledge the experts who were involved in the interviews for my case study research and contract exploration: Brenden Bradley and Gregory Gangitano Parnters at Gordon \& Rees LLP Construction Group Associates, Raymond Kahl - Urban Design Group, Mandeep Bhari - Associate Provost for Planning \& Design USC, Jesus Fuentes - Project Manager Matt Construction, Inh Ling - AECOM Design Manager, Rob Foster - Project BIM Manager Sundt, Dan Russell - Director of Construction Technology Sundt, Cliff Baker - Assistant General Counsel Sundt, and Howard Atkinson - Virtual Construction Engineer Sundt. Without their knowledge and their readiness to participate, the validation of this thesis could not have been successful.

Finally, I must express the greatest gratitude towards my parents and boyfriend for the continuous support throughout the journey of researching and writing this thesis. This accomplishment would not have been possible without them. Thank you.

Author

Kathleen Worden 


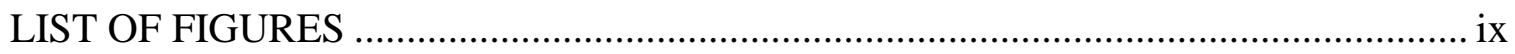

\section{CHAPTER}

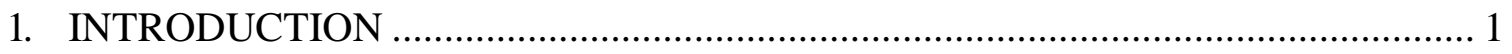

2. WHAT ARE INTEGRATED DELIVERY PROJECTS? ........................................ 4

2.1 Integrated Project Delivery and Collaboration.................................................. 4

2.2 Design Build............................................................................................. 7

2.3 Steps of Integrated Project Delivery .............................................................. 8

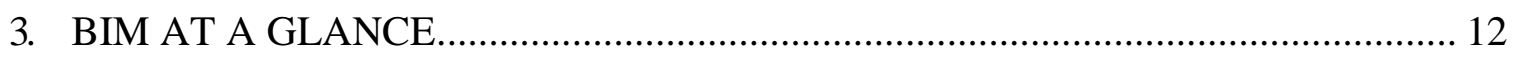

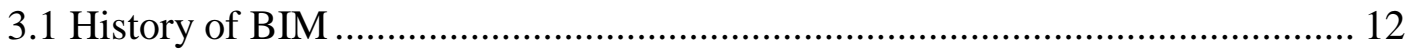

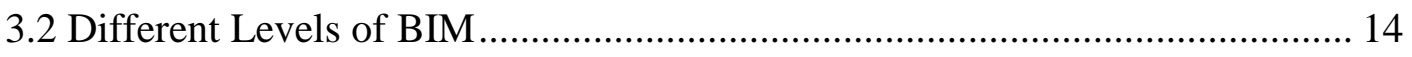

3.2.1 3D Model........................................................................................... 15

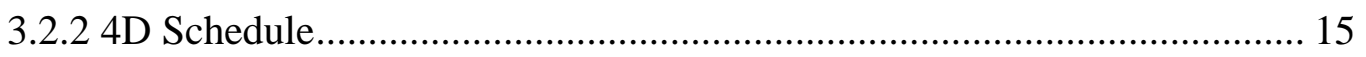

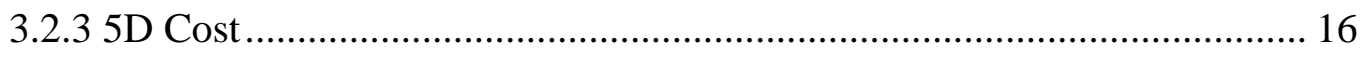

3.2.4 6D \& 7D Lifecycle Management …………………………………........ 16

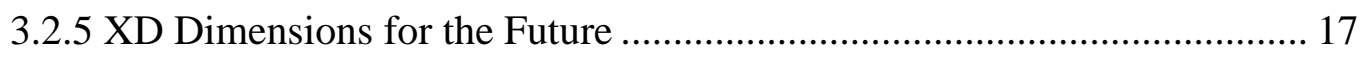

3.2.6 Level of Detail in BIM (LOD) ……………….................................... 18

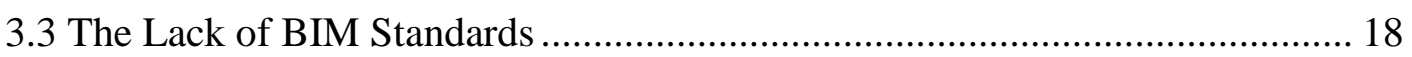

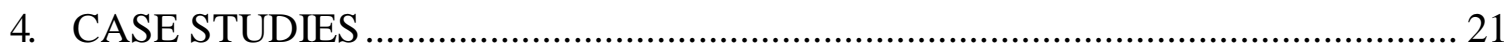

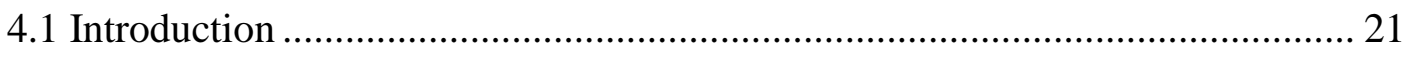

4.2 San Diego International Airport …………………....................................... 22

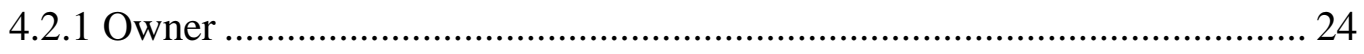

4.2.2 Designer/Contractor ............................................................................ 24 


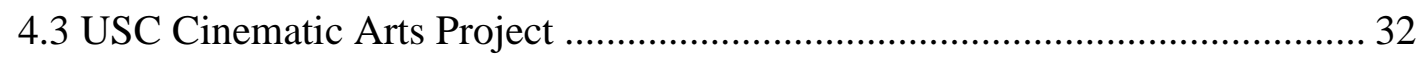

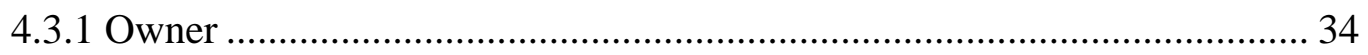

4.3.2 Designer/Contractor .................................................................... 36

4.3.3 The Development of the BIM Package and using it in Practice............... 37

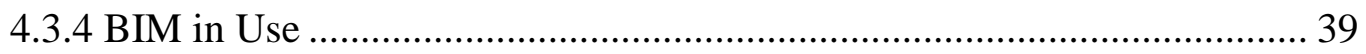

4.3.5 BIM Usage Examples:............................................................ 40

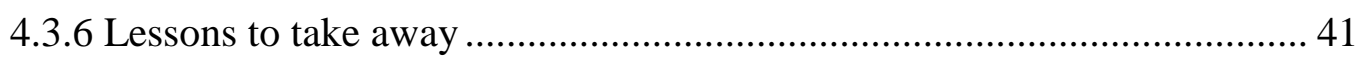

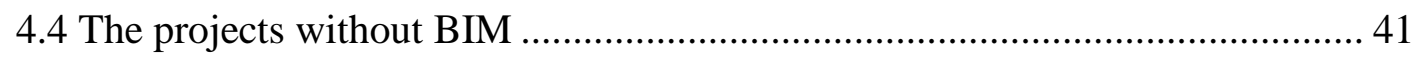

4.4.1 Instance 1: If owner had not requested BIM being used ...................... 41

4.4.2 Instance 2: If the Designer didn't model ......................................... 42

4.4.3 Instance 3: If the Contractor didn't get involved................................. 42

4.4.4 Conclusion ............................................................................... 42

5. CONTRACT DOCUMENTS FOR IPD AND BIM ........................................... 44

5.1 What is a Construction Contract? .......................................................... 44

5.2 Design and Constructability Contract .................................................. 45

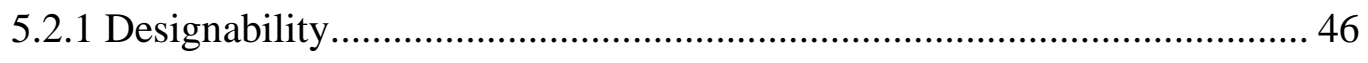

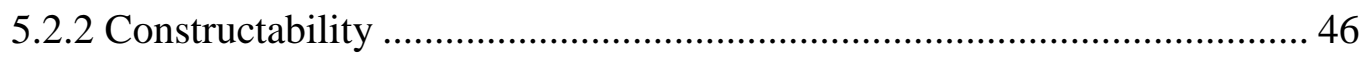

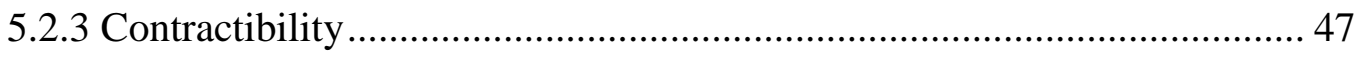

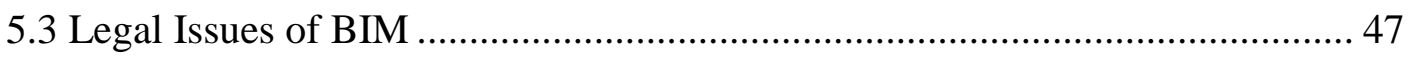

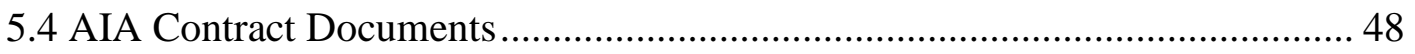

5.4.1 Integrated Project Delivery: A Guide ................................................ 49

5.4.2 AIA Digital Practice Documents ..................................................... 49 
5.5 AGC Consensus Docs ....................................................................... 51

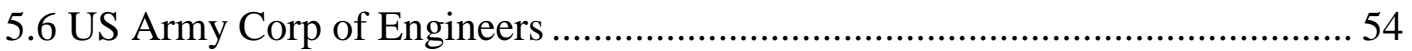

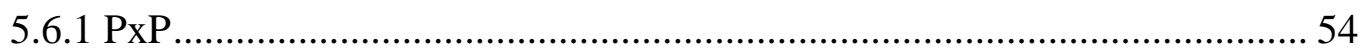

5.6.2 Minimum Modeling Matrix (M3) ........................................................ 56

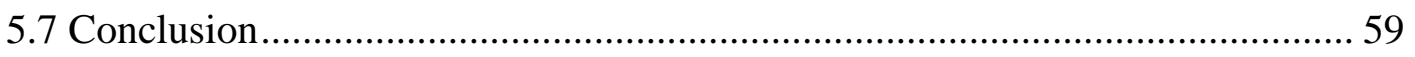

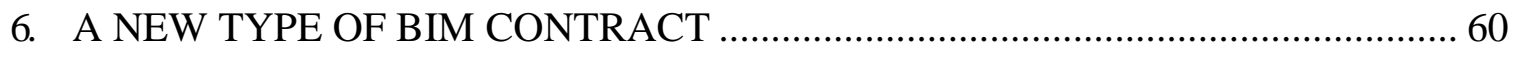

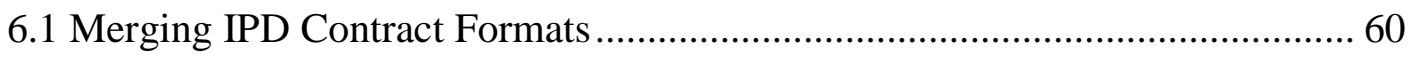

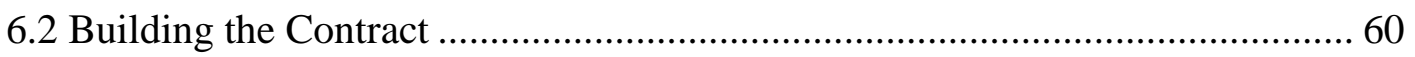

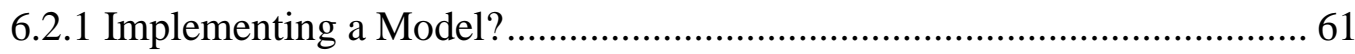

6.2.2 Model Implementation Contract Checklist ....................................... 62

6.2.3 Implement Checklist and Model into Project...................................... 62

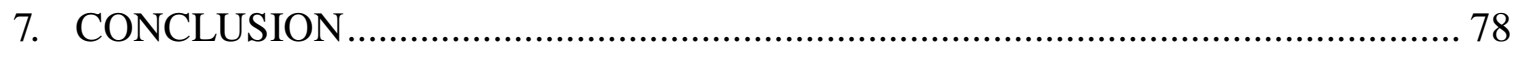

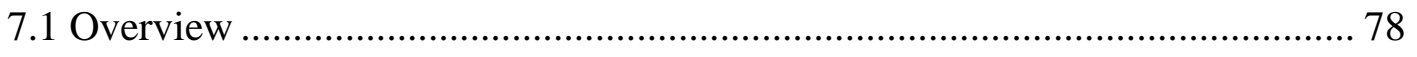

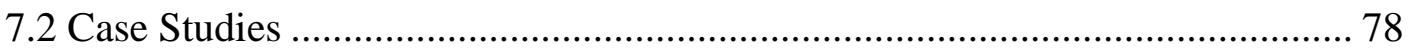

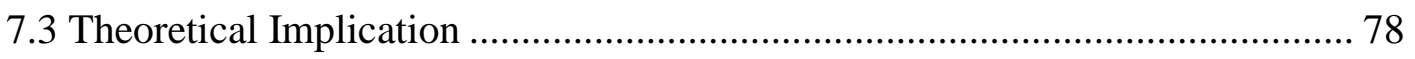

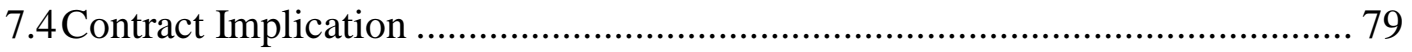

7.5 Recommendation for Future Research ................................................... 79

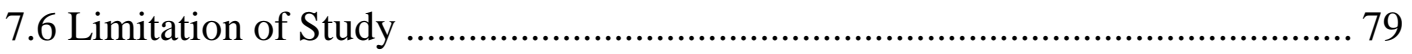

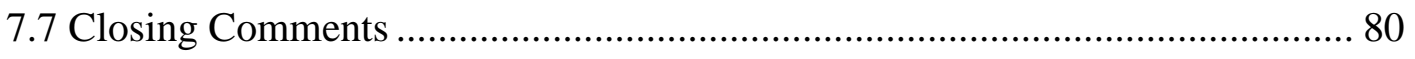

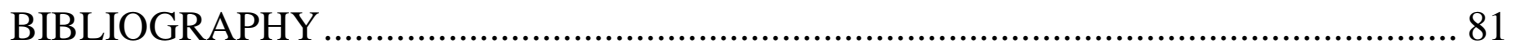

APPENDICES

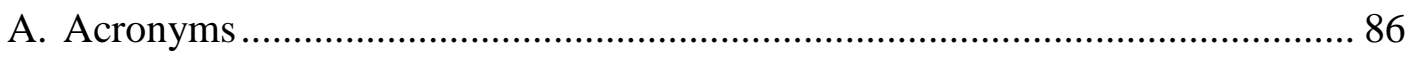




\section{LIST OF FIGURES}

Figure Page

Figure 1: Design-Bid-Build Contract Configuration ............................................. 4

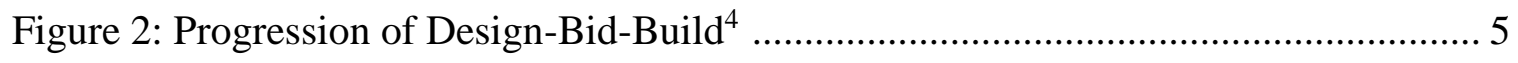

Figure 3: Design-Build - Team Working Together................................................. 7

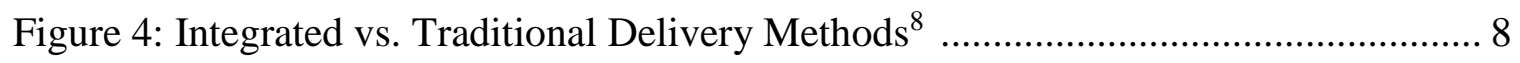

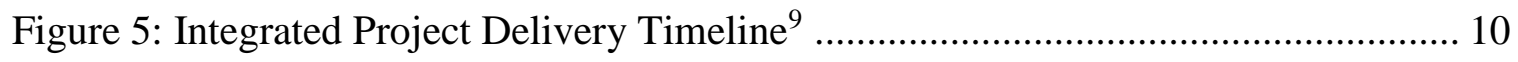

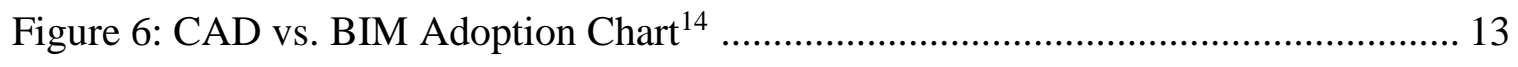

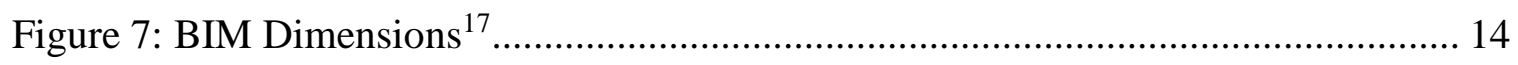

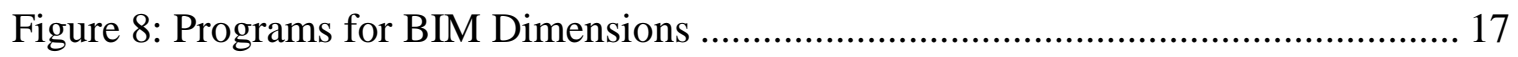

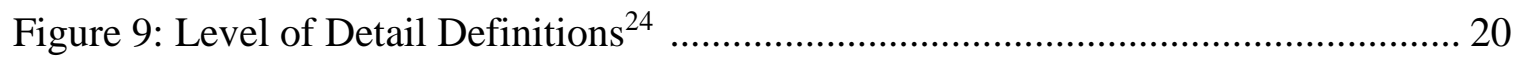

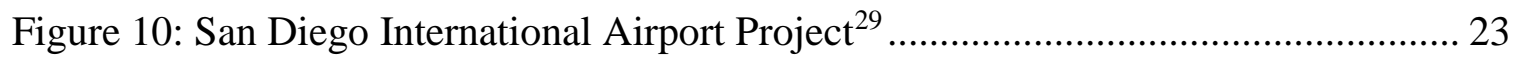

Figure 11: LOD for San Diego International Airport Landside Project ${ }^{31}$..................... 26

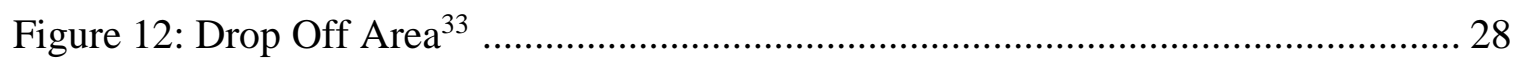

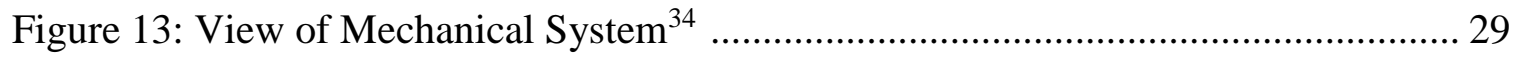

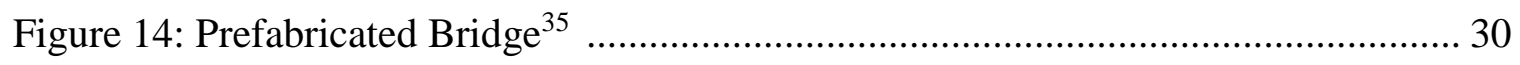

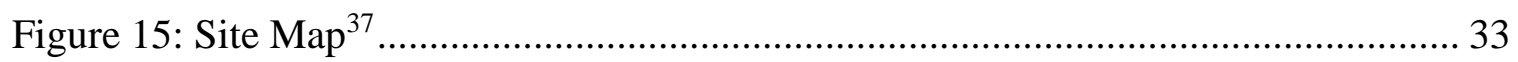

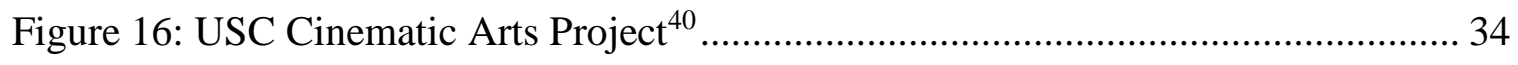

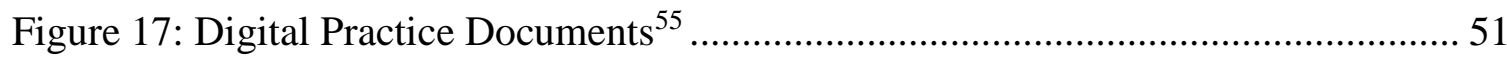

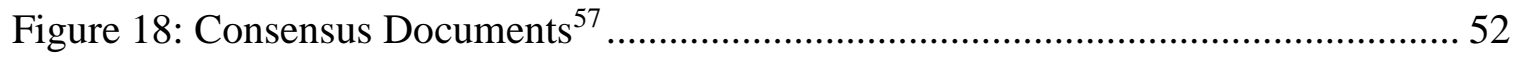

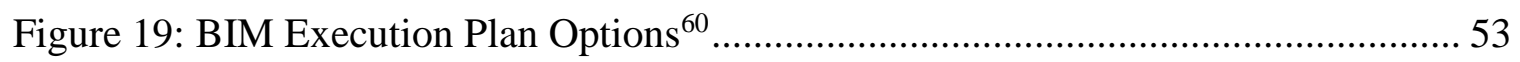

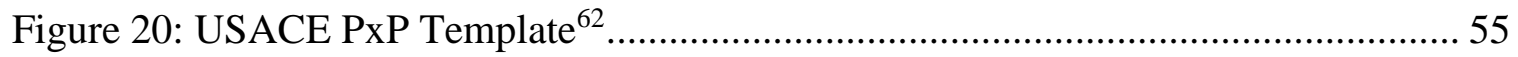

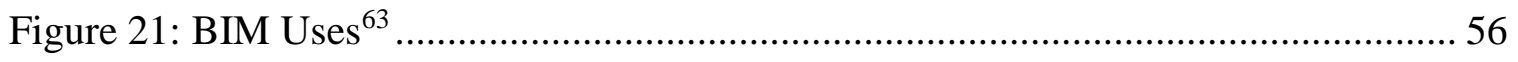


Figure 22: LOD Definitions ${ }^{65}$

Figure 23: M3 Grading Rubric ${ }^{66}$... 


\section{CHAPTER 1}

\section{INTRODUCTION}

Shelter is one of the primordial needs. Human ancestors would seek shelter, and when they could not find it, they would build it. As civilizations developed, the need for construction leadership grew.

In ancient times, most notably the Renaissance, the Master Builder was the person who knew all about the building in progress. They were the ones responsible for the design and the construction of the project. No changes were lost due to communication issues, because all relevant details were in one person's head. Contracts were verbal and sealed with a handshake. A separation between design and building began around the end of the Renaissance and the term 'Master Builder' fell out of favor, leading to today's view of segregated professions involved on a building project. Recently, there has been an increased effort to collaborate and communicate more efficiently and effectively through the process of Integrated Project Deliveries (IPD) and Building Information Modeling, or BIM. Although the road to IPD might have taken hundreds of years, BIM is a much younger concept.

In the late 1980's, Computer Aided Drafting (CAD) drawings became widely accepted in the design and building industry. CAD programs allowed details to be copied and pasted onto plans and enabled quicker turn around for construction documents. There is a higher chance for mistakes with the attempt to increase productivity. For example, typical details provided by design firms might not be relevant for the project at hand or possibly not changed from the last project the detail was used on. This increases the discrepancies between what the Designer wants and what the Contractor is trying to build. Builders begin to build what was drawn and then will have to change it later in the 
project. This puts the Owner in the middle of a battle between the Designer and the General Contractor and costs the Owner a great amount of money. It also creates an industry of animosity, cluttered with paper trails and contracts in order to avoid lawsuits rather than collaboration and a building that everyone is happy with.

The Integrated Delivery Processes has started a new trend by having a collaborative team of Designers, Constructors, and Owners working side by side to create a successful project. Although it is not just one person doing the job of a Master Builder, it goes back to the same principle of one entity making the decisions for the project.

Often, the design and construction teams guide the Owner through the construction process, especially if it is the Owner's first building experience. This involves explaining drawings, and understanding and interpreting what the Owner wants in the project. The Designers and Contractors have used Building Information Modeling as a tool to model, estimate, and schedule to make the delivery process smoother. BIM can help ease the owners into the world of their project. At first, many owners might not buy into the use of BIM, thinking it is a waste of time which leads to higher project costs. It is becoming more of an industry standard since it is being adopted by many parties involved in the building process. It has become more common that the Owners now approach Designers and Contractors to request that BIM be used on the project. The question is, how extensive should the BIM process be and when should it be implemented on an IPD building project? Those answers rely on what the contract documents require, and how the team decides that the BIM process should be implemented.

The research methodologies used for this study are mixed. Extensive literature reviews of relative texts, articles, and journals were used. Interviews of representatives 
involved on building projects include: Designers, General Contractors, and Owners as case studies. Lastly, suggestions of guidelines for the use of BIM in a project will be made that could possibly lead to the next generation of BIM. 


\section{CHAPTER 2}

\section{WHAT ARE INTEGRATED DELIVERY PROJECTS?}

\subsection{Integrated Project Delivery and Collaboration}

In the Renaissance, there were two parties involved in the construction process: the Owner and the Master Builder. When the Master Builder concept faded, the two party process became more complex with the addition of a third member to establish the more traditional standards of today. The Master Builder's job was split into two: Contractor and Designer. The Designer was needed to draw out plans, and Contractor needed to be out in the field directing construction. ${ }^{1}$ The Contractor/Designer dichotomy evolved into what is called the Design-Bid-Build (DBB) method. DBB divides the Designer and the Contractor by having separate contracts with the Owner, while the Designer and Contractor still have direct contact with each other in order to get the project completed.

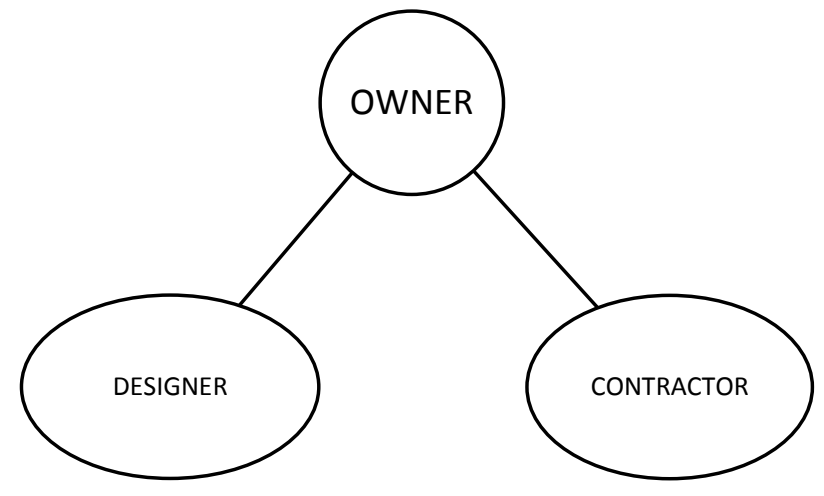

Figure 1: Design-Bid-Build Contract Configuration ${ }^{2}$

\footnotetext{
${ }^{1}$ Kymmell, Willem. Building Information Modeling Planning and Managing Construction Projects with 4D CAD and Simulations. New York: McGraw-Hill, 2008.

2 Jackson, Barbara J. Design-build: Design-build Essentials. 1st ed. Clifton Park, N.Y.: Delmar/Cengage, 2011.
} 
The title Design-Bid-Build accurately represents its meaning. It is a very linear process with no overlap with parties involved in the building process. First, an Owner approaches a design team to prepare a design and place it up for bid. The design team consists of (but not limited to) an Architect, Structural Engineer, Mechanical Engineer, and Civil Engineer. Contractors then bid on the construction of the project based on what is in the contract documents (plans and specifications) after they are complete.

Construction begins as soon as the contract documents are handed over. This is what is known as the "traditional delivery method" today because it is the most frequently used delivery system. ${ }^{3}$

\section{Design}

\section{Bid}

\section{Construction}

Figure 2: Progression of Design-Bid-Build ${ }^{4}$

As seen in Figure 1, the Owner has one contract with the Designer and one with the Contractor, and then the Designer and Contractor talk: it is a very disjointed process. ${ }^{5}$

Separated and disconnected with the different parties, communication is difficult, and

\footnotetext{
${ }^{3}$ Forbes, Lincoln H., and Syed M. Ahmed. "Information and Communication Technology/Building Information Modeling." In Modern Construction Lean Project Delivery and Integrated Practices. Boca Raton, FL: CRC Press, 2011, 8-9.

${ }^{4}$ Jackson, Barbara J. Design-build: Design-build Essentials. 1st ed. Clifton Park, N.Y.: Delmar/Cengage, 2011, 43.

${ }^{5}$ Weygant, Robert S.. BIM Content Accessed Development: Standards, Strategies and Best Practices. Hoboken, NJ, USA: Wiley, 2011. January 27, 2015. ProQuest ebrary, 7.
} 
often things get lost in translation. Many times, the Contractor has to make assumptions, or they simply place bids on documents that are often incomplete, then place a Request for Information (RFI) with the Designer post bid date. If the design is affected by the RFI, there is a potential change order. With change orders, comes a higher cost to the project. ${ }^{6}$

Recently, industry has been working towards a new direction of delivery method: Integrated Project Delivery (IPD).

IPD is a project delivery approach that integrates people, systems, business structures, and practices into a process that collaboratively harnesses the talents and insights of all participants to reduce waste and optimize efficiency through all phases of design, fabrication, and construction. Integrated Project Delivery principles can be applied to a variety of contractual arrangements and Integrated Project Delivery teams will usually include members well beyond the basic triad of owner, architect [designer], and contractor. At a minimum, though, an Integrated Project includes tight collaboration between the owner, the architect [designer], and the general contractor ultimately responsible for construction of the project, from early design through project handover ${ }^{7}$.

This idea of Integrated Project Delivery evokes the original idea of the Master Builder; but instead of it being a single person, it is a single entity comprised of all parties (Owner, Designer, and Constructor) needed to make a successful project. The Owner can consist of an Owner's representative, an organization of people that the project is built for, or just the owner themselves. The Designer, like in the DBB method, can be comprised of designers such an Architect, Structural Engineer, Mechanical Engineer, and Civil Engineer. The Constructors can be made up of the General Contractors and Subcontractors. The IPD team can realistically be a large body of team members.

${ }^{6}$ Kymmell, Building Information Modeling Planning and Managing Construction Projects with 4D CAD and Simulations, 7.

${ }^{7}$ Jackson, Barbara J. Design-build: Design-build Essentials. Clifton Park, N.Y.: Delmar/Cengage, 2011, 33. 
Through the repetitive nature of drawings, changes in the design can often affect multiple pages in the construction documents. In a traditional contract method, changes or mistakes missed at bid time would require an RFI. With an integrated system, changes can be made in the drawings with as little as a phone call.

One method of IPD that uses collaboration methods extensively is a Design Build contract approach.

\subsection{Design Build}

Figure 3 below shows each major party in the building process as equal importance by the size of the circles. The circles are overlapped representing the collaboration between the parties. Where all three circles meet represents the contract that they all follow. All of the major participants in the project are working together, under the same contract.

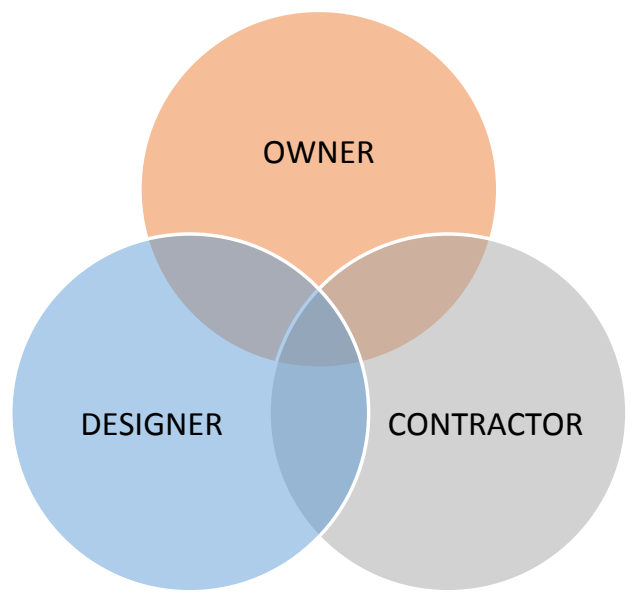

Figure 3: Design-Build-Team Working Together

The group shares equal liability under a single agreement contract while performing their respective roles. This form of contract delivery requires great trust and integration between the team members. The goal of this contract method is to come to an agreement 
of what is best for the project, rather than what is best for the individual, hence sharing the liability in the contract.

\subsection{Steps of Integrated Project Delivery}

Below, Figure 4 is a flow chart provided by a Committee of the Integrated Project Delivery Task Force sponsored by McGraw Hill Construction and the American Institute of Architects California Council for the working definition of Integrated Project Delivery. This group is composed of Architects, Engineers, Contractors, Subcontractors, Owners and Attorneys.

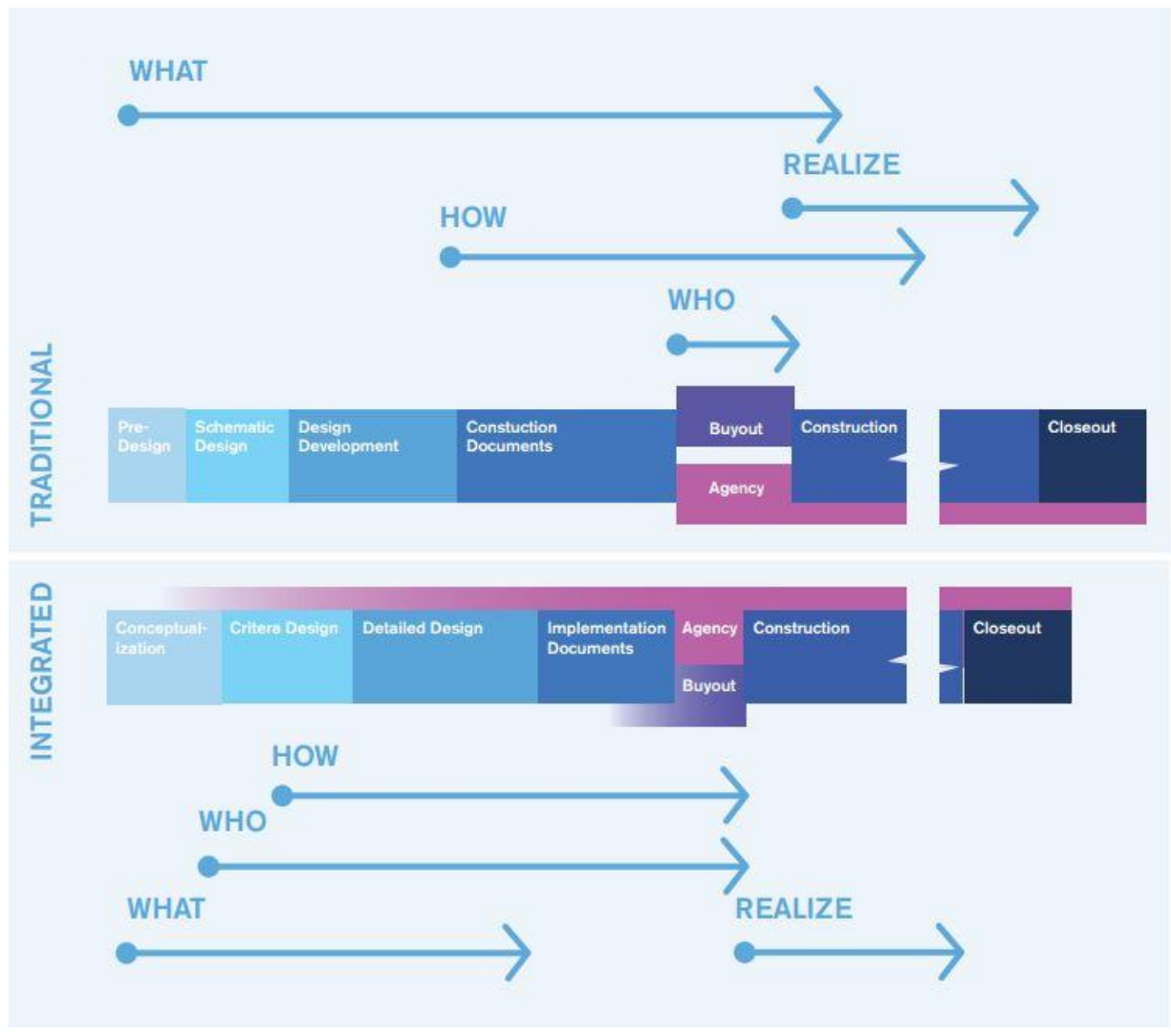

Figure 4: Integrated vs. Traditional Delivery Methods ${ }^{8}$

8 "Integrated Project Delivery - A Working Definition." American Institute of Architects California Council, 2007. Accessed June 15, 2015.

https://www.dir.ca.gov/das/hcc/WorkingDefinition.pdf. 
The layout of the flowchart is based on a working definition of Integrated Project Delivery and the segments of the chart should be tailored to the integrated delivery method chosen. The model used for the traditional method of delivery is very similar, but the differences lie in the what, who, and how of the project.

The "what" of the project in Figure 4 defines what is being built; the differences between the two methods lie in the duration. The traditional method defines "what" all the way through Construction, where the timeframe is shorter and is established in Detailed Design for IPD. Where the methods mostly differ is when the "who" and the "how" are implemented into the delivery systems. The "who" represents the people who are involved in the building process. This includes Constructors and major Subcontractors that will be involved. In a traditional format, the "who" are not brought onto the project until it is time to bid on the project, or buyout. With this, there is a high potential for RFIs and change orders due to the Subcontractors not being involved early. Which leads to the "how" segment of the flowchart. It is the Subcontractors who help with the construction logic. If the "how" is being dealt with during the construction documents phase, again there will be a higher probability of RFIs and change orders. With the integrated system implementing the construction logic earlier on the project, it can be implemented into the construction documents.

It is important to remember that this process will only be as good as the team makes it and will not work if the team does not work in a collaborative manor. The flow chart in Figure 5 involves the use of BIM. 
Figure 5: Integrated Project Delivery Timeline ${ }^{9}$

Conceptualization is where the dream of a project begins. Although this thesis focuses on the three major parties, it does take a small army to complete a project. Conceptualization is where a project team, which includes a large group including the Owner, Designer, and Contractor involved in the project come together and provide input for a successful job. Performance goals, a preliminary schedule, and cost estimate are created. BIM can also be used to capture key parameters.

Criteria Design is a trial and error period. Many ideas are implemented and evaluated by the team to see if they satisfy the project parameters. The design team can discuss potential design solutions before a full extent of models are put into place to prevent wasting design time. After discussions, models may be made for exploration of the design.

Detailed Design allows for finalization of the design ideas. All of the major building systems are fully designed during this period and Subcontractors are able to give input for system coordination.

Implementation Documents involves how the design of the building will be implemented and the compilation of documents to move forward with building. The Construction Document (CD) phase can be significantly shortened due to Subcontractors working side by side with the Designers for major systems that will be implemented into

${ }^{9}$ Ibid. 
the building during the design phase. This allows for the shop drawing process to be virtually eliminated. If the Subcontractor uses a detailed model of the system, then there isn't a need for them to re-draw the system in 2D. The model can be exported as a 2D drawing.

Agency Review and Buyout stages happen at about the same time. During permitting, the construction team is compiling a list of potential bidders for the project so it can be bought out right after plans are approved. Agency Review is similar to traditional methods for permitting and design review. Buyout really only occurs if the Subcontractors were not included in the integrated team.

Construction in an integrated project setting is where all the front-loaded work is recognized. The team tends to have a better understanding of the design, submittals are complete, there are fewer RFI's, and will mostly be on site for quality control and cost monitoring.

Closeout, like traditional methods, touch on compensation incentives or penalties, warranty, record drawings, and punch list. 


\section{CHAPTER 3}

\section{BIM AT A GLANCE}

\subsection{History of BIM}

In 1975, Charles Eastman wrote an article for the AIA journal titled The Use of Computers Instead of Drawings In Building Design. This article was not about drawing in $2 \mathrm{D}$ on computers, but modeling in $3 \mathrm{D}$ on computers, written before the industry adoption of Computer Aided Drafting (CAD). He had the idea that models were good tools for spatial realization, but it was easier to change drawings rather than handmade models ${ }^{10}$. So why not use the computer to model in 3D? It seems that industry was not ready for that giant step. It wasn't until the mid-1980s that CAD drawings were introduced into the design and construction industry. ${ }^{11}$ According to Figure 6, it took about 12 years for CAD to replace hand drawings. Using CAD allowed drafters to work faster rather than draw everything by hand. Erasing a line or eliminating an entire detail could be done with a few clicks of a mouse rather than an electric eraser.

2D drawings are still used, but do have flaws. Many times, 2D drawings are not linked to each other, so when there is a change made in a drawing, it will not transfer the change throughout a set of plans. For example, if a beam is changed on a plan view, the detail of the beam will not change. There are also times that a detail on paper will reference other details, which will also be unaffected if just changed in 2D. Another issue is when Owners, Designers, and Contractors have to look at 2D drawings and try to

\footnotetext{
${ }^{10}$ Eastman, Charles M. "The Use of Computers Instead of Drawings in Building Design." AIA Journal 63, no. 3 (1975): 46-50.

${ }^{11}$ Deutsch, Randy. BIM and Integrated Design Strategies for Architectural Practice. Hoboken, N.J.: Wiley, 2011. Accessed January 27, 2015. ProQuest ebrary, 4.
} 
visualize a building. It takes a lot of skill to get to this level, and often times, it might be the owner's first building. ${ }^{12}$

3D came into view in the early 1980's. Models were created by developing software programs that could build "virtual projects" that helped project details and improved visualization of elements on projects. ${ }^{13}$ There were many times when the $3 \mathrm{D}$ model was used for marketing purposes, where a rendering was created for people to see the finished product. Or there was the other extreme of a 3D walkthrough of the building, allowing the designers and the client to see the layout of the building in a finished state.

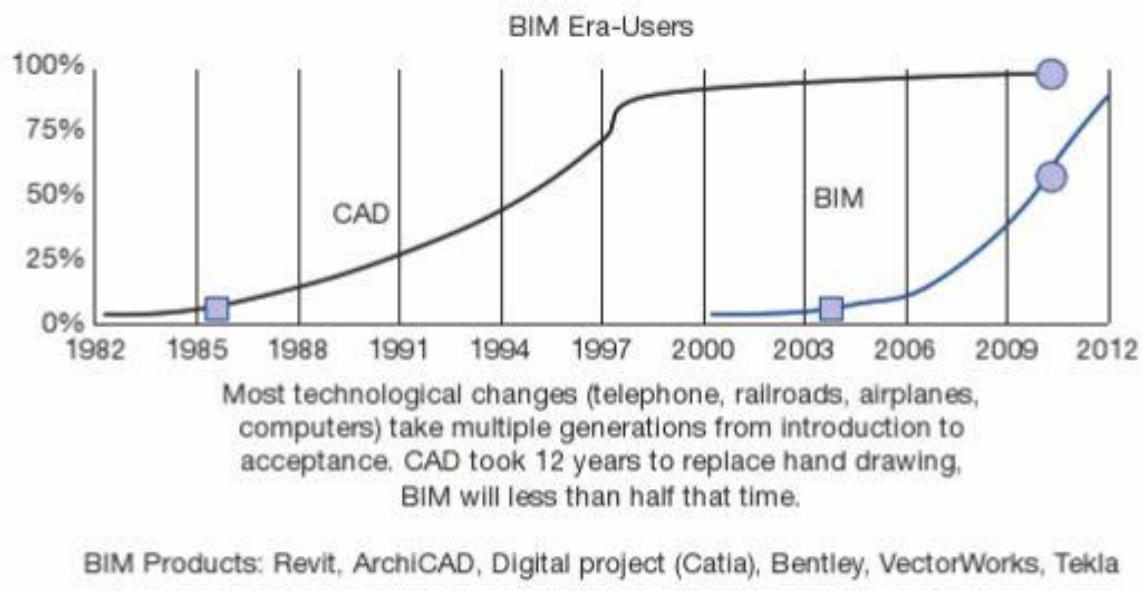

Figure 6: CAD vs. BIM Adoption Chart ${ }^{14}$

It wasn't until the early 2000's that BIM became a buzzword, and became adopted by project teams. BIM was mostly being used by Subcontractors for prefabrication purposes, and then was adopted by General Contractors for clash detection and

${ }^{12}$ Kymmell, Willem. Building Information Modeling Planning and Managing Construction Projects with 4D CAD and Simulations. New York: McGraw-Hill, 2008, 47.

13 Ibid., 38.

${ }^{14}$ Deutsch, Randy. BIM and Integrated Design Strategies for Architectural Practice. Hoboken, N.J.: Wiley, 2011. Accessed January 27, 2015. ProQuest ebrary, 4. 
prevention purposes. But unlike Contractors, it seemed to be a slower adoption process for Designers and Owners alike.

Architects, as a group, have been the most hesitant with Integrated Project Delivery, particularly when BIM is involved, mostly legal concerns and higher initial costs. ${ }^{15}$ If the hired team is hesitant about implementing BIM, the Owner will probably not want to take the risk of paying for a tool that they may never use again or may not see it as valuable.

\subsection{Different Levels of BIM}

There are quantitative and qualitative elements in the BIM process. The quantitative element is in that BIM tools can spit out measurable quantities using metrics.16 This includes elements of BIM such as the cost estimation and scheduling. Qualitative BIM elements are more visual: clash detection, sustainability analysis, and facilities management. Both quantitative and qualitative are broken into "dimensions" to further develop the information systems.

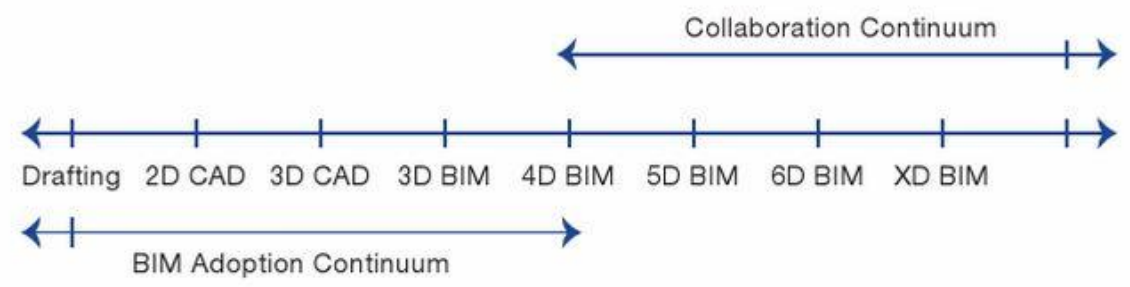

Figure 7: BIM Dimensions ${ }^{17}$

As BIM has been developing in the building industry, different dimensions have been "invented" for all items of concern in quantitative and qualitative elements of a project to

${ }^{15}$ Jackson, Barbara J. Design-build: Design-build Essentials. 1st ed. Clifton Park, N.Y.: Delmar/Cengage, 2011. Page 32.

${ }^{16}$ Deutsch, BIM and Integrated Design Strategies for Architectural Practice, 15.

${ }^{17}$ Deutsch, Randy. BIM and Integrated Design Strategies for Architectural Practice. Hoboken, N.J.: Wiley, 2011. Accessed January 27, 2015. ProQuest ebrary, 92. 
make sure all information is considered. Even though BIM has reached up to a $7^{\text {th }}$ dimension, it is far from being fully developed to further the study of a building.

\subsubsection{D Model}

"3D models are created for schematic design, design development, construction documentation, and sometimes record drawings." ${ }^{18}$ 3D models can also be used for "clash detection" which checks to see if two objects are occupying the same space. For example, a plumbing pipe could run into a steel beam within a building. The computer can detect when there is a clash between the beam and the pipe. Through the 3D process, objects can be moved to a new location and changes taken into account before they are built in real time. ${ }^{19}$

\subsubsection{D Schedule}

$4 \mathrm{D}$ or 3D+Cost, consists in linking a 3D model of building elements with the schedule of construction tasks in order to simulate the space transformation process over time. ${ }^{20}$ The schedule is tied to elements that are modeled to add logic to the model. This also allows for a time lapse video to be made. This is where you can watch the model develop in real time.

\footnotetext{
${ }^{18}$ Kensek, Karen M. Building Information Modeling. London: Routledge, 2014, 21.

${ }^{19}$ Ibid., 24

${ }^{20}$ Conrad Boton, Sylvain, and Gilles Halin. "Designing Adapted Visualization for Collaborative 4D Applications." Automation in Construction, 2013, 152-67. Accessed January 28, 2015.
} 


\subsection{3 $5 \mathrm{D}$ Cost}

$5 \mathrm{D}$ is often noted as 4D + Cost, but the fifth dimension essentially takes the quantities and volumes that were entered into the $3 \mathrm{D}$ model to provide cost related data. It can be used for an economic evaluation system and time related data as duration needed for implementation of construction works. ${ }^{21}$ With this, the model can show a schedule of billing based on the percentage of completion.

\subsubsection{D \& 7D Lifecycle Management}

Recently, Designers and Contractors have been expanding on the ideas of BIM and incorporating other details into the model to follow the life cycle of the building with 6D. Some of these aspects include: indoor environmental quality and sustainability management, operations and maintenance, and space planning. ${ }^{22}$

The 7D aspect of models is generally used by the occupants of the building. For example, the facilities manager can access this model when there is an element system down. The facilities manager can look at an interactive model that will show if there is a broken part within a system. With the location of this part, it will reduce the amount of time and possibly money with replacing the part. It can also show things such as when a filter needs to be changed. An example of this is shown with the COBie system mentioned on the USC Cinematic Arts Project introduced later in Chapter 4.

\footnotetext{
${ }^{21}$ Popov, Vladimir, Virgaudas Juocevicius, Darius Migilinskas, Leonas Ustinovichius, and Saulius Mikalauskas. "The Use of a Virtual Building Design and Construction Model for Developing an Effective Project Concept in 5D Environment." Automation in Construction, 2009, 357-67.

22 Karen M Kensek, Building Information Modeling, London: Routledge, 2014, 29.
} 


\subsubsection{XD Dimensions for the Future}

6D and 7D have just been recently claimed by information sectors for use on projects. There may be more dimensions that can add to the "information" portion of Building Information Modeling in the near future, the need just hasn't been discovered yet. Below, the chart shows a list of some programs that might be used in the various dimensions used in BIM.

\begin{tabular}{|c|c|c|}
\hline & Program & Provider \\
\hline \multirow{4}{*}{$2 \mathrm{D}$} & AutoCAD & Autodesk \\
\hline & Revit & Autodesk \\
\hline & ArchiCAD & Graphisoft \\
\hline & Vectorworks Architect & Vectorworks \\
\hline \multirow{4}{*}{ 3D BIM for Visualization } & Revit & Autodesk \\
\hline & ArchiCAD & Graphisoft \\
\hline & Tekla & Trimble \\
\hline & Vectorworks Architect & Vectorworks \\
\hline \multirow{3}{*}{ 3D BIM for Clash Detection } & Navisworks & Autodesk \\
\hline & $\begin{array}{l}\text { Vico Office Contructability } \\
\text { Manager }\end{array}$ & Trimble \\
\hline & Solibri & \\
\hline \multirow{3}{*}{ 4D Scheduling } & Microsoft Project & Microsoft \\
\hline & Primavera & Oracle \\
\hline & Vico Office Schedule Planner & Trimble \\
\hline \multirow{2}{*}{ 5D Cost } & Quantity Takeoff & Autodesk \\
\hline & Vico Cost Planner & Trimble \\
\hline \multirow{5}{*}{ 6D Sustainability } & Ecotect & Autodesk \\
\hline & Green Build Studio & Autodesk \\
\hline & EcoDesigner & Trimble \\
\hline & Hevacomp & Bentley \\
\hline & ArchiCAD & Graphisoft \\
\hline \multirow{3}{*}{ 7D Facilities Management } & FM: Interact & \\
\hline & COBie & \\
\hline & Bentley Facilities & Bentley \\
\hline \multirow{2}{*}{ Field Management } & BIM 360 Field & Autodesk \\
\hline & Bluebeam Revu & Bluebeam \\
\hline
\end{tabular}

Figure 8: Programs for BIM Dimensions 


\subsubsection{Level of Detail in BIM (LOD)}

There are five levels of detail for modeling. They range from the conceptual level to the highest level of representational precision. The levels are as follows: 100 conceptual, 200 approximate geometry, 300 precise geometry, 400 fabrication, 500 as-built. Figure 9 shows level of detail for the different uses of BIM. Establishing the different levels of detail is important for each stage of the project. Without establishing this, there may be a possibility where an element may have too much detail to where it is no longer beneficial to the stage of the project. Or the opposite effect, where there may not be enough information to continue with other elements within the project.

\subsection{The Lack of BIM Standards}

Although BIM is becoming an industry standard, it has to be decided within the project team that it will be used as a tool that helps propel the project forward. It is just a matter of what dimensions of BIM are needed. There is not really an industry standard as to how BIM should be implemented and to what degree of detail is needed through the BIM process.

A large amount of the information about Building Information Modeling is focused on the technology that is used rather than the people who are using it. It is important to know about the people behind the technology, and the reason they are using it:

communication and collaboration. ${ }^{23}$ It may be stated within the team's contract that there needs to be the "use of BIM" or a BIM implementation plan within the project design and delivery, but without a minimum or a limit. There could be a chance that the team incorporates a large amount of information into the model that may not really be needed,

${ }^{23}$ Randy Deutsch, BIM and Integrated Design Strategies for Architectural Practice (Hoboken, N.J.: Wiley, 2011), accessed January 27, 2015, ProQuest ebrary, 9. 
with the misconception that all of the elements need to be utilized. There are many elements for Building Information Modeling that can be used, not all of them have to be if they are not needed for the collaboration process. For example, the project team may only want to utilize 3D modeling and 7D facilities management elements, but not the others in between. As long as the BIM process starts with 3D, other elements with "information" can be added if needed for the requirements of the project as it progresses. BIM as an idea provides support in collaborative design with the expectation for proper decisions to follow. 


\begin{tabular}{|c|c|c|c|c|c|}
\hline Level of Detail $>$ & 100 & 200 & 300 & 400 & 500 \\
\hline \multicolumn{6}{|l|}{ Model Content } \\
\hline $\begin{array}{l}\text { Design \& Coordination } \\
\text { (function / form / behavior) }\end{array}$ & $\begin{array}{l}\text { Non-geometric } \\
\text { data or line } \\
\text { work, areas, } \\
\text { volumes zones, } \\
\text { etc. }\end{array}$ & $\begin{array}{l}\text { Generic } \\
\text { elements shown } \\
\text { in three } \\
\text { dimensions } \\
\text { - maximum size } \\
\text { - purpose }\end{array}$ & $\begin{array}{l}\text { Specific } \\
\text { elements } \\
\text { Confirmed 3D } \\
\text { Object Geometry } \\
\text { - dimensions } \\
\text { - capacities } \\
\text { - connections }\end{array}$ & $\begin{array}{l}\text { Shop drawing/ } \\
\text { fabrication }\end{array}$ & $\begin{array}{l}\text { As-built } \\
\text { - actual }\end{array}$ \\
\hline \multicolumn{6}{|l|}{ Authorized uses } \\
\hline 4D Scheduling & 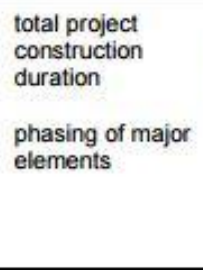 & $\begin{array}{l}\text { Time-scaled, } \\
\text { ordered } \\
\text { appearance of } \\
\text { major activities }\end{array}$ & $\begin{array}{l}\text { Time-scaled, } \\
\text { ordered } \\
\text { appearance of } \\
\text { detailed } \\
\text { assemblies }\end{array}$ & $\begin{array}{l}\text { Fabrication and } \\
\text { assembly detail } \\
\text { including } \\
\text { construction } \\
\text { means and } \\
\text { methods } \\
\text { (cranes, man- } \\
\text { lifts, shoring. } \\
\text { etc.) }\end{array}$ & \\
\hline Cost Estimating & $\begin{array}{l}\text { Conceptual cost } \\
\text { allowance } \\
\text { Example } \$ / s f \text { of } \\
\text { floor area, } \\
\$ / \text { hospital bed, } \\
\$ / \text { parking stall, } \\
\text { etc. } \\
\text { assumptions on } \\
\text { future content }\end{array}$ & $\begin{array}{l}\text { Estimated cost } \\
\text { based on } \\
\text { measurement of } \\
\text { generic element. } \\
\text { E.g., generic } \\
\text { interior wall. }\end{array}$ & $\begin{array}{l}\text { Estimated cost } \\
\text { based on } \\
\text { measurement of } \\
\text { specific } \\
\text { assembly. E.g., } \\
\text { specific wall } \\
\text { type. }\end{array}$ & $\begin{array}{l}\text { Committed } \\
\text { purchase price } \\
\text { of specific } \\
\text { assembly at } \\
\text { Buyout. }\end{array}$ & Record costs \\
\hline Program Compliance & $\begin{array}{l}\text { Gross } \\
\text { departmental } \\
\text { areas }\end{array}$ & $\begin{array}{l}\text { Specific room } \\
\text { requirements }\end{array}$ & $\begin{array}{l}\text { FF\&E, } \\
\text { casework, utility } \\
\text { connections }\end{array}$ & & \\
\hline Sustainable Materials & LEED strategies & $\begin{array}{l}\text { Approximate } \\
\text { quantities of } \\
\text { materials by } \\
\text { LEED categories }\end{array}$ & $\begin{array}{l}\text { Precise } \\
\text { quantities of } \\
\text { materials with } \\
\text { percentages of } \\
\text { recycled/locally } \\
\text { purchased } \\
\text { materials }\end{array}$ & $\begin{array}{l}\text { Specific } \\
\text { manufacturer } \\
\text { selections }\end{array}$ & $\begin{array}{l}\text { Purchase } \\
\text { documentation }\end{array}$ \\
\hline $\begin{array}{l}\text { Environmental: Lighting, } \\
\text { Energy use, air movement } \\
\text { Analysis/Simulation }\end{array}$ & $\begin{array}{l}\text { Strategy and } \\
\text { performance } \\
\text { criteria based on } \\
\text { volumes and } \\
\text { areas }\end{array}$ & $\begin{array}{l}\text { Conceptual } \\
\text { design based on } \\
\text { geometry and } \\
\text { assumed system } \\
\text { types }\end{array}$ & $\begin{array}{l}\text { Approximate } \\
\text { simulation based } \\
\text { on specific } \\
\text { building } \\
\text { assemblies and } \\
\text { engineered } \\
\text { systems }\end{array}$ & $\begin{array}{l}\text { Precise } \\
\text { simulation based } \\
\text { on specific } \\
\text { manufacturer } \\
\text { and detailed } \\
\text { system } \\
\text { components }\end{array}$ & $\begin{array}{l}\text { Commissioning } \\
\text { and recording of } \\
\text { measured } \\
\text { performance }\end{array}$ \\
\hline \multicolumn{6}{|c|}{ Other uses may be identified and developed } \\
\hline \multicolumn{6}{|l|}{ Exiting and circulation } \\
\hline \multicolumn{6}{|l|}{ Code compliance } \\
\hline Etc. & & & & & \\
\hline
\end{tabular}

Figure 9: Level of Detail Definitions ${ }^{24}$

${ }^{24}$ Jim Bedrick, "Organizing the Development of a Building Information Model."

American Institute of Architects, 2008. Accessed June 15, 2015.

http://www.aia.org/groups/aia/documents/pdf/aiab078868.pdf. 


\section{CHAPTER 4}

\section{CASE STUDIES}

\subsection{Introduction}

In the projects discussed in this chapter, there is a range of how BIM is implemented into the projects. The first project had a few lines written into the contract requiring the use of BIM, known as a "BIM implementation plan," but without an extent of the information to be implemented or how the information should be used. With the BIM implementation plan set at the beginning of the project, the plan continued to evolve as it was discovered what should be used where. The second project is where the donor for the building requested the use of BIM, with very strict guidelines as to how it should be implemented. Since then, the owner has made these guidelines a standard for their future buildings.

These case studies were prepared to supplement an understanding of BIM's influence on a building project. The case studies show two very different projects and how they are approached with varying integrated project types and implementation of BIM.

Contributors to the project, Owner's Representatives, Designers, and Contractors were asked to participate in interviews about their project experience. The contributors were requested to follow a common group of questions such as project type, size, their role and responsibilities in the project, collaboration type, and how BIM played a role in their project involvement. The parties involved in the building process view things from different perspectives. Often times there was an agreement on the successes found when implementing BIM into the collaborative building process. A representative of each 
party of the building project was asked to participate and explain BIM's role in the project. What were the pitfalls, and what were the successes?

The projects introduced are the San Diego International Airport, and the USC Cinematic Arts building. Both demonstrate the use of BIM in the most efficient ways possible for the design and construction, while satisfying the requests of the owners to implement BIM and collaboration into the project.

\subsection{San Diego International Airport}

The San Diego International Airport recently expanded Terminal 2. The project was split into two different sections of the expansion: Airside Expansion which is shown in blue in the Figure 10, and Landside Expansion which is shown in green in the Figure 10. The overall expansion included the West side of Terminal 2, the Central Utility Plant, and Landside Infrastructure Improvements. This was "the largest improvement project in the airport's history," and involved multiple contractors. ${ }^{25}$ In total the project was 3.3 million square feet. It was delivered in a combined Design-Build and Fast Track Delivery system with a total of 153 design and management staff on site. ${ }^{26}$ Fast track works with the Design Build method to move the construction forward while the design is still being completed. With this many people on site and the size of the project, any lack of communication is an occupational hazard that could lead to great confusion onsite.

The main focus for this case study will be the Landside Infrastructure Improvements, which was led by Designers AECOM and builders Sundt Construction. This portion of the project "introduced a new 1,300 foot-long dual-level departures roadway in front of

${ }^{25}$ San Diego International Airport Projects, "The Green Build," accessed July 1, 2015, http://www.san.org/Airport-Projects/The-Green-Build.

${ }^{26}$ Rob Foster (Project BIM Manager) in discussion with the author, March 2015. 
Terminal 2."27 This new layout would separate the arriving and departing traffic. "The construction also included two outdoor, curbside check-in lobbies, an expanded traffic center, two pedestrian sky bridges, a new USO and parking Management office building, six bridge overpasses, new roadways, and reconstructed parking lots" 28

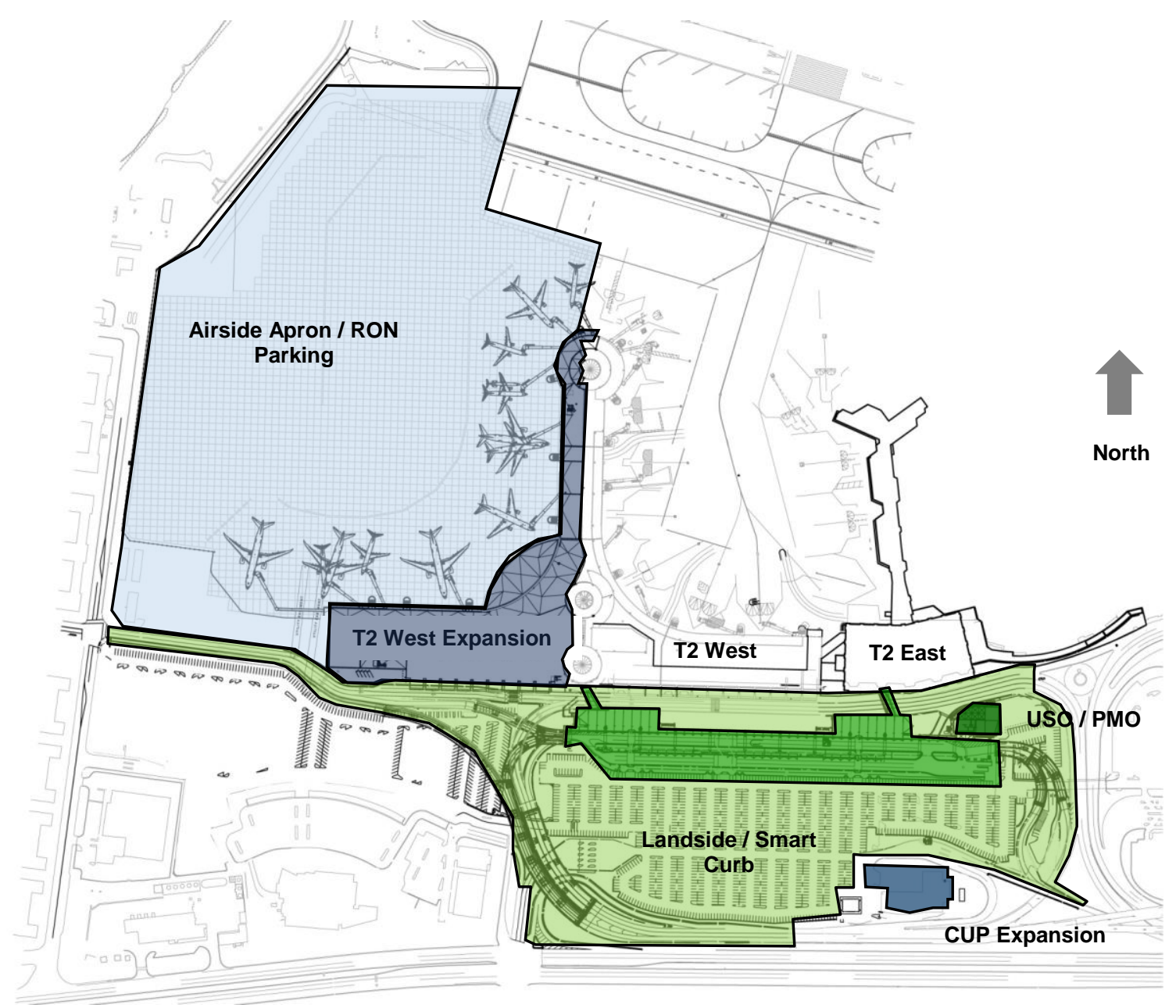

Figure 10: San Diego International Airport Project ${ }^{29}$

${ }^{27}$ Ibid.

${ }^{28}$ Sundt, "San Diego International Airport Terminal 2 Landside Expansion | Sundt," 2014, accessed July 1, 2015. http://www.sundt.com/projects/san-diego-internationalairport-landside-package-int-jv-so-cal-share/.

${ }^{29}$ Rob Foster, Contract Documents, 2014, Presentation, San Diego International Airport, San Diego. 


\subsubsection{Owner}

The owner for this project was the San Diego County Regional Airport Authority. There were about 40-50 people who represented the "Owner." The Owner was mostly involved with the big conceptual items, and were mostly concerned about how things looked and that they worked.

The use of BIM was a driven requirement for the contract by the client, who emphasized that BIM be used as much as possible during the project. Within the Qualification Based Selection (QBS), there were a few paragraphs stating that BIM was to be used and the GC was to create a BIM execution plan, and use it through the duration of the project. One specific requirement that was called out in the Request for Proposal (RFP) was the use of 4D and material quantity extraction.

\subsubsection{Designer/Contractor}

This project really fits to the criteria of an integrated project team, by the use of a design-build contract. It was truly a collaborative team.

\section{Designers:}

Inh Ling was part of the civil design team as CAD manager, who worked for URS Corporation, now known as AECOM. URS is an infrastructure and support services firm in markets such as transportation, facilities, environmental, energy, water, and government services. Inh states that URS had been using BIM company wide, primarily in vertical building. But this was the first project for the San Diego Office, and the only lateral project that had been done while Inh worked for URS. Vertical Building might include office buildings, apartment complexes, or hospitals, where lateral building may consist of roadways and bridges. 
Because this landside construction was connecting to existing conditions, and parallel to the terminal expansion project, there was a lot of work to prevent conflicts with utilities and structural elements, and for him, the most stressful and most successful part was using BIM.

Contractors:

The Contractor for this job, was actually a Joint Venture (JV) team between Sundt and Kewit. Rob Foster, a Sundt employee and Project BIM Manager, is the GC representative for this case study. Sundt led the process of creating the BIM execution plan that would be followed throughout the project.

\subsubsection{BIM in Practice}

The Contract and BIM Execution Plan for the Landside Infrastructure Improvements Project included:

Contract Section 1.2.1.10 Building Information Modeling (BIM and Virtual Design and Construction) (VD\&C). Multi-dimensional modeling process that allows the parties to view construction components in three dimension, with the principle intent of using the model to present the design to decision makers, analyze the functionality on operability of facilities, and highlight conflicts and inefficiencies before the impact of construction. Three dimensional model thus generated shall be further extended to incorporate construction schedule and sequencing information as a fourth dimension, and cost information as a fifth dimension. The model shall be used throughout the Preconstruction and Construction Phases of the Work as a principle tool for the communication/facilitation of the Work. The Airport Authority intends to use the model beyond final completion to assist its facility management efforts. ${ }^{30}$

The BIM execution plan was an agreement between JV partners and the Design team about what was to be included. Some examples include what a Subcontractor would provide in their models, what the designers needed to include for the project design, how

30 Ibid. 
models would be exchanged for information needed by other parties, tolerances for elements in the project, and the final document turnover.

Because a BIM model evolved with the project, the BIM execution plan evolved as well. There were about 5 different iterations of the BIM execution plan throughout the project, and refined as the project went on. The initial draft was more of an outline and used for the design process. As subcontractors were hired, details became more refined as shown in Figure 11. Based on the Level of Detail (LOD) definitions provided, it was decided what LOD was needed for each trade. When the project started to come to a close, the model was being updated as an "as-built" model.

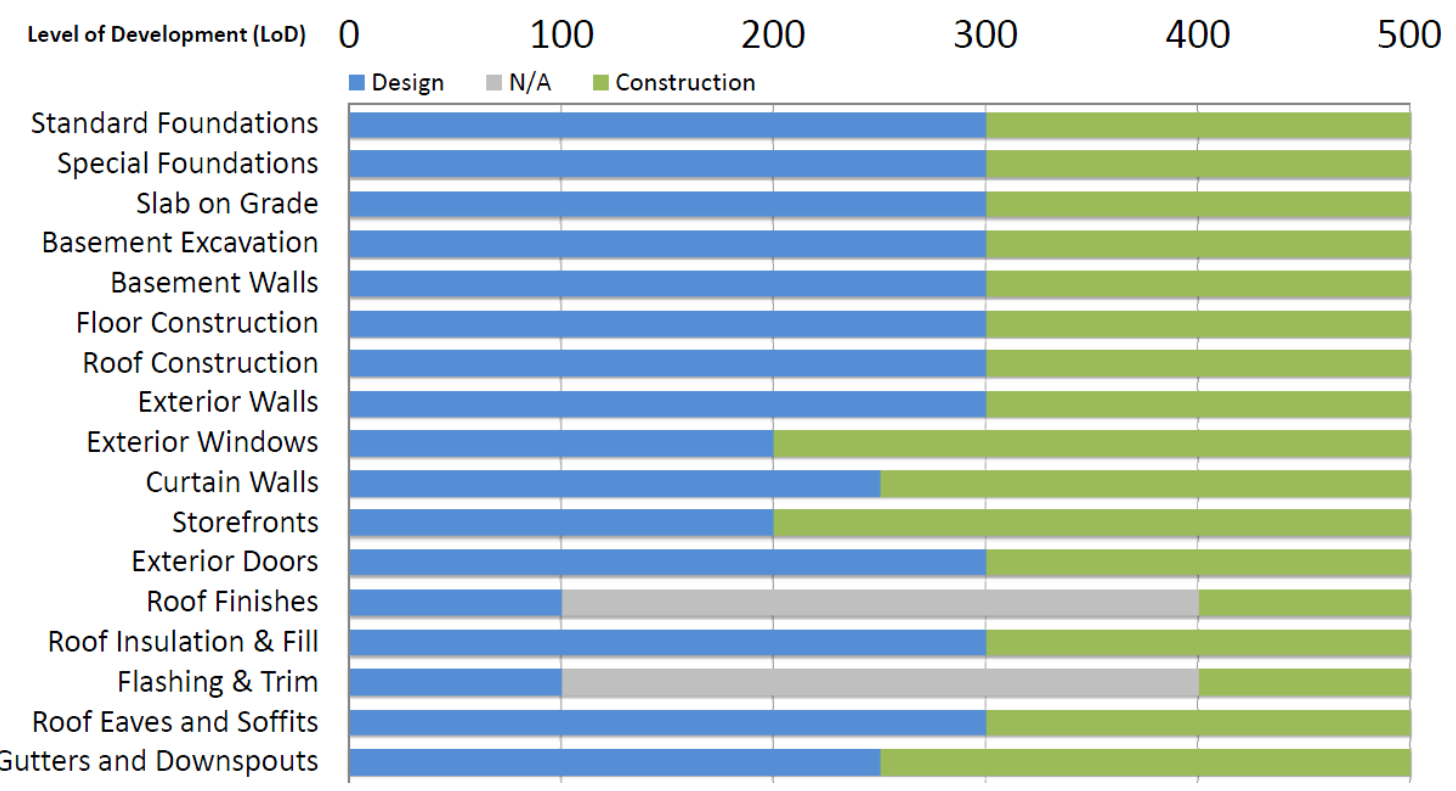

\section{Figure 11: LOD for San Diego International Airport Landside Project ${ }^{31}$}

The team specifically stated that they were going to use BIM to provide deliverables developed to enhance: effective communication, collaboration and cooperation. With this in mind, the team had four significant concepts that they would incorporate into their

\footnotetext{
${ }^{31}$ Rob Foster, Applying BIM to Large Public Construction Programs/Projects, 2013, Presentation, San Diego International Airport, San Diego.
} 
BIM execution plan: evolution from BIM for 2D to BIM for Project, model as a source of truth, use design BIM for construction and beyond, and continuous BIM quality assurance or quality control (QA/QC). ${ }^{32}$ Evolution from BIM for 2D to the Project is the idea of producing more than $2 \mathrm{D}$ contract documents through a $3 \mathrm{D}$ program. Its goal is to strive for accuracy of design intent and be comprehensive enough to allow others to design or coordinate with other scopes. Modeling a source of truth branches from the idea that the model can be rely on accuracy in work sessions so stakeholders and team members to make informed decisions throughout the project. Design BIM for construction and beyond is the idea that there isn't a point to modeling something more than once. So the model that is used in the design phase will also be used in the construction phase. This would hold the architectural model to a high standard of accuracy. Continuous BIM QA/QC would conduct weekly coordination meeting as soon as $3 \mathrm{D}$ content was available until the end of the project. BIM walkthroughs were also submitted to the owner as a monthly report. The team believed that through implementing BIM, the team was able to achieve the concepts listed above, they were in a good position to use the BIM model to support effective communication.

\subsubsection{BIM usage examples: Through the eyes of Rob Foster}

1. Meetings - Initially, BIM was utilized by those on site, but it was hard to convince participants in the meeting that BIM was helpful, despite the fact that the owner requested it be used during the project. Rob states that during Owner Architect Contractor (OAC) meetings, that the model would be placed on the screen, but people would rather try and sketch out what they were trying to portray. It wasn't

${ }^{32}$ Ibid. 
until 3-4 months into the project that people decided that looking at the model was more helpful than trying to sketch it out. Soon enough, every meeting involved the model and it provided a "crutch" in order for the meeting to proceed. But from the design-build team's side, having the model made it a little easier for the owner to make decisions. The model could be changed right in the meeting for the owner to see the result. If they liked it, then it was approved on the spot and ready to proceed in the field. If the owner didn't like the changes made to the design, then it was easy to revert the model to its original state. It allowed for constant critique. Below is an example of two options for the shade structure at the curb presented in a meeting for the owner to make a final decision. According to Rob, the decisions made in the meetings saved hundreds of redesign hours going back and forth with whether the design is what the owner really wanted.
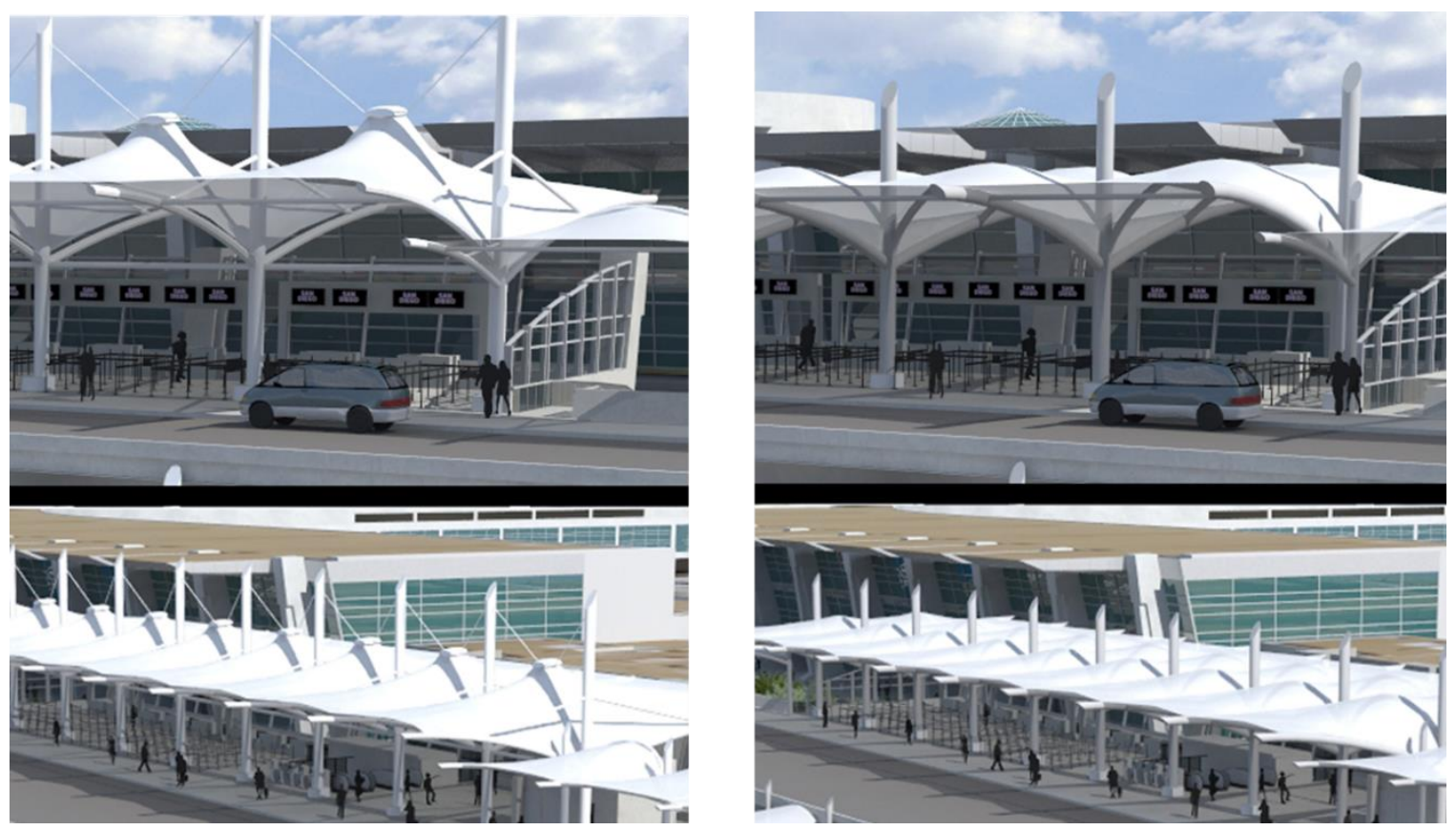

Figure 12: Drop Off Area ${ }^{33}$

33 Ibid. 
Another use for the model in meetings was to show the owner that some changes could not be done, visually explaining what the end product would look like. It could also show why something couldn't be built a certain way or why it would not work design-wise. An example of this was the discussion of putting a mechanical system on the roof of the terminal drop-off. This is perfectly normal, except it could be seen from the road as a car drove up to the terminal. The final decision was to raise the parapet up a few feet, so it would only be seen from one corner on the road. See Figure 13 below for a view of what it would have looked like if installed with the initial design.

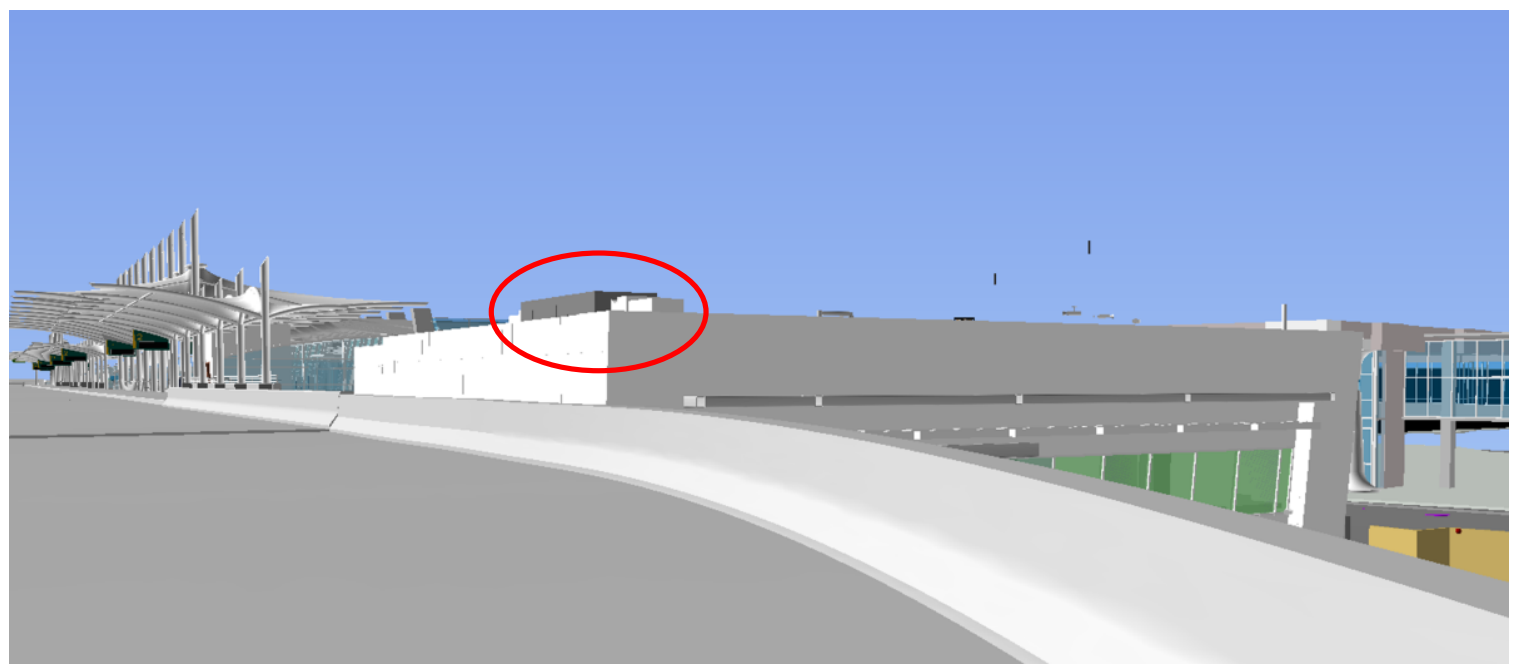

Figure 13: View of Mechanical System ${ }^{34}$

2. $4 \mathrm{D}$ - One of the most profound uses of BIM in this project was a simulation for the installation of the two pedestrian bridges. Building the bridges a traditional way would have caused the roadway through the airport to be closed for a long duration. An idea to minimize the amount of closures in the roadway needed to

\footnotetext{
${ }^{34}$ Rob Foster, Transportation and Utility Projects Case Studies Using BIM, 2013, Presentation, San Diego International Airport, San Diego.
} 
be presented: prefabrication. Not only were the bridges prefabricated, it was one continuous piece to be placed. When the bridges were first brought into the picture, a simulation was done, showing that the way the bridges were originally presented to be placed, would in fact not work. Originally, the bridge was planned to swing into place in a counter-clockwise motion, but through simulation, it was discovered that it wouldn't fit. The team had to go back to the drawing board and approach it from a different angle, literally. The rotation was switched to a clockwise motion to swing into position. Without this simulation, the team may never have figured out the lack of clearance. It made it with just 4 inches of clearance. With this simulation, the extended schedule was mitigated, and the bridges were installed overnight by closing the roadway for only a matter of hours. The BIM simulation broke down the placement of the bridges right down to the minute.

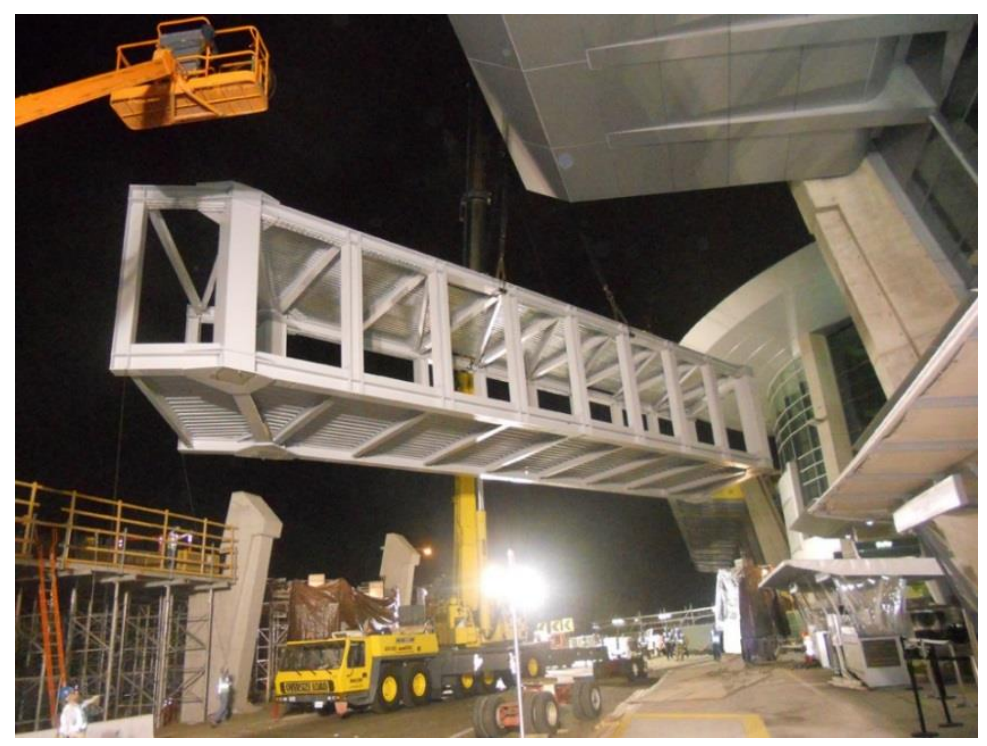

Figure 14: Prefabricated Bridge ${ }^{35}$

${ }^{35}$ Sundt, "Pedestrian Bridge Placement Takes Many Months, Plus a Single Night | Sundt," accessed June 04, 2015, http://www.sundt.com/media/blog/2012/05/30/1811/. 
The team found that tying the schedule and simulation for large events, such as the bridge, useful. They also found that if the model was tied to the entire project schedule, it wasn't really valuable. The project was so large in size that it would take about a week for someone to tie the model and schedule together, and by that time the model was out of date. It was also a problem if the model was changed during a meeting or a clash detection. The schedule would then no longer serve its purpose. It was a team decision not to continue to tie the model to the entire schedule for the sake of time management even though it was listed as a project requirement. The entire team found that they did fill the requirement by tying it to the model once.

3. Increased cost and schedule delay prevention - A specific example that came up with preventing extra costs and delays to the project was the use of $3 \mathrm{D}$ civil modeling and clash detection of underground utilities and with trees, foundation, excavation, storm drain lines and other underground elements. During the project, potholes had to be dug with excavators to confirm the current utilities were located correctly on the existing plans. An existing model done on a previous phase helped eliminate the need to dig between $300-400$ potholes, which cost about $\$ 1000$ each. Sundt was also able to model the existing utilities. A large discovery was made when incorporating their model with the existing utilities model. An existing utility line that belonged to the government had an easement which was located at the end of the proposed storm drain line. The models was able to show the clash before the trench was dug and pipe placed. Without the use of BIM, the end of the line would have been reached to find that a few 
thousand feet would have to be re-routed to avoid the existing government utility line. The clash detection saved the project money in the change order and rebuilding process. Not only that, but Sundt was able to provide a new model including all of the potholes that were done, existing, and new utilities to the owner for future building. It is estimated that about $95 \%$ of the clash issues for storm drains were mitigated through BIM clash detection meetings.

\subsection{USC Cinematic Arts Project}

The USC Cinematic Arts Complex is a series of seven main buildings totaling 270,000 square feet. This building complex was completed in 2013, and has a large range of spaces that include: sound dubbing stages, editorial labs, screening rooms, sound production studios, mixing rooms, theatres, classrooms, conference rooms, and faculty offices. ${ }^{36}$ The first two phases were done by Hathaway Dinwiddie, and the last phase, Phase III, was done by Matt Construction.

Because it was not a typical contract format from the beginning, this project was unique. Initially, the donor was going to build the building and then turn over the keys to USC. Instead, it became a partnership with USC and the donor. The collaboration didn't make the design any easier. The donor came forward with expectations, and the Designer had to work with rigid guidelines set by the university. The Contractor assisted with designing elements of the building. Although this may not have been a textbook DesignBuild or IPD project, it has elements within the project that show a large amount of collaboration in those contract types.

\footnotetext{
${ }^{36}$ USC School of Cinematic Arts s.v. "Cinematic Arts Complex," accessed May 2, 2015, http://cinema.usc.edu/facilities/complex.cfm.
} 
The University of Southern California found that the building that held the original Cinematic Arts program was dated. The facilities did not accommodate the amount of students admitted to the program. At first, the university suggested that they upgrade the old building by renovating and incorporating an expansion. After some feasibility studies, it was found too difficult to tie a newer building into the old building. It was going to cost as much, if not more, to incorporate into the existing building. Instead, it was decided a new building would be built.

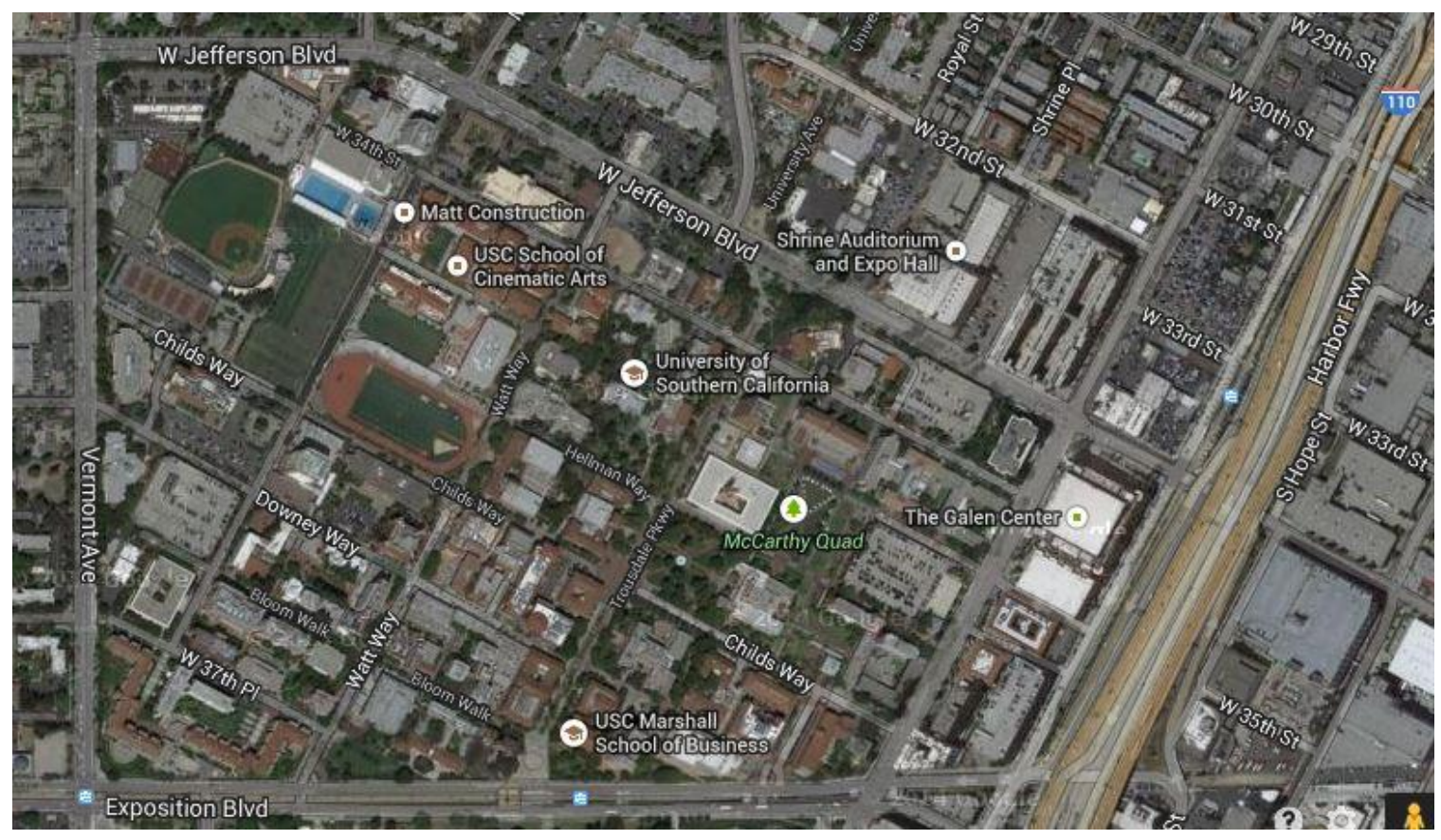

Figure 15: Site Map $^{37}$

A concurrent issue was the original building needed to be in use while the new building was being built. Tearing down the existing building and replacing it with a new one was not an option. A new discussion began about available land on campus property,

\footnotetext{
${ }^{37}$ University of Southern California [map], 2015, Scale undetermined; generated by Google; using "Google.com, Inc." https://www.google.com/maps/place/University+of+Southern+California/@34.0223563,$\underline{118.2873111,17 \mathrm{z} / \mathrm{data}=! 3 \mathrm{~m} 1 ! 4 \mathrm{~b} 1 ! 4 \mathrm{~m} 2 ! 3 \mathrm{~m} 1 ! 1 \mathrm{~s} 0 \times 80 \mathrm{c} 2 \mathrm{c} 7 \mathrm{e} 49 \mathrm{c} 71 \mathrm{a} 5 \mathrm{ed}: 0 \times a a 905 \mathrm{a} 5 \mathrm{bb} 427 \mathrm{a} 2 \mathrm{c}}$ $\underline{4 ? \mathrm{hl}=\mathrm{en}}$
} 
and where the new building complex could be built. ${ }^{38}$ Once this was decided, the first of the three phases began. This project would include the first building built on campus in the last 20 years. Phase III will be the main focus of this case study. This building is 62,500 square feet, consisting of screening rooms, audio sensitive rooms, grant research labs, faculty offices, and support spaces. ${ }^{39}$

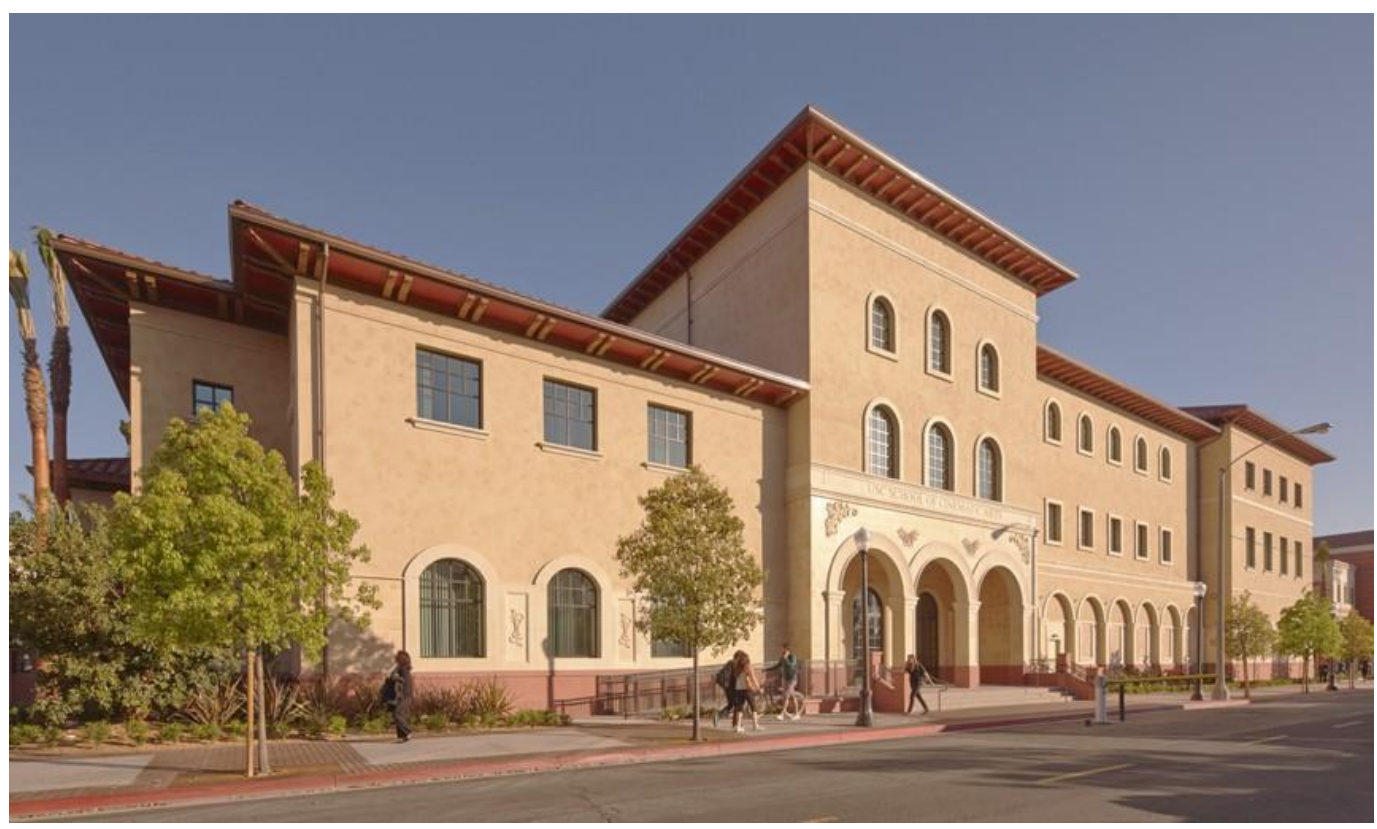

Figure 16: USC Cinematic Arts Project ${ }^{40}$

\subsubsection{Owner}

University of Southern California, the Owner, received a donation to build the complex. Due to security, the donor will remain anonymous. USC is obviously not one person, so there was input from many sectors within the USC community to make this

${ }^{38}$ USC School of Cinematic Arts s.v. "Cinematic Arts Complex," accessed May 2, 2015, http://cinema.usc.edu/facilities/complex.cfm.

${ }^{39}$ Jesus Fuentes (USC Cinematic Arts Project Manager), Telephone interview by author, December 2, 2014.

${ }^{40}$ USC School of Cinematic Arts Phase III s.v. "Projects," accessed July 07, 2015, http://www.mattconstruction.com/project-detail/bim-projects/usc-school-of-cinematicarts-phase-iii. 
project successful including: the donor, the president of the university, facilities management, and the cinematic arts faculty that would be conducting classes within the building. The different representatives of the owner had different focuses. The president of the university has an image of what the campus should look like, stressing a consistency of appearance throughout the university. The donor had expectations as to what would be included in the building that would make the students successful in the cinematic industry. Faculty provided input for lecture halls and labs, while facilities management provided feedback for systems that would be key for the functionality of the building. The Facilities Management (FM) group was brought on from the first day: the first time USC took this approach for a new project. Facilities Management gave input on the different mechanical systems and their designs for upkeep of the building. ${ }^{41}$ Through the use of BIM throughout the project, and the discovery of the capability of the team, they were able to create a fully working model for the facilities management team to use for tracking systems and the status of the equipment. This was helpful for the very small facilities management team. Because of this system, they were able to run the building with the supervision of one full-time and one part-time employee, rather than hiring even more. This was the first building on campus that had incorporated this sort of system, and was the basis of BIM implementation plan that the university has since utilized in new building projects. USC had previously had a system for facilities management which would only give the data for equipment in the building. With the new program, the data was attached to the 3D model which was also capable of localizing the problem within the model rather than just stating that there was an issue with that piece of

${ }^{41}$ Mandeep Bhari, (USC Cinematic Arts Project Owner's Representative), Telephone interview by author, January 7, 2014. 
equipment. Just by the end of Phase I, there was a completely developed model to turn over that had operations software that included parts lists, operating manuals for equipment, and most of the finishes and building systems that were in the building. All of the contracts for USC are a Design Bid Build contract format, and initially did not have a BIM/VDC line item in their contract. It was a team decision to implement BIM into Phase I of the project and work hand in hand with the owner's design team. It continued to be used throughout the other two phases.

\subsubsection{Designer/Contractor}

This project is particularly unique in the design process because the donor had a large impact on the design of the buildings. Urban Design Group worked alongside USC and the donor to adhere to same design theme that the school had held since 1929: Romanesque revival style. The same design team, Urban Design Group, was used throughout the three phases. The work done during the first two phases set the stage for when Matt Construction joined the team for Phase III. For example, Facilities Management already had input on what mechanical systems were needed. It was necessary to work closely with Matt Construction and the Subcontractors to complete a design that would work best for post occupancy maintenance.

The Phase III project initially went out to bid with three or four other General Contractors (GCs). Matt Construction was awarded the project, and decided on a contract method called Design Assist. Jesus Fuentes, a Project Manager for Matt Construction, explains this method procures the contract for the construction, and then assists Designers, Architects or Engineers of Record, with the design through a separate contractor. After the design is complete, the Designers sign off on the design provided 
by the Design Assist. All of the mechanical, electrical, plumbing, fire sprinkler, and fire alarm systems were designed with a DB method. There was a period of about two months for the Designers to coordinate with the Subcontractors to help finish their design drawings in order to submit for permitting. The only subcontractor that Matt Construction did not have direct management over was the audio/visual subcontractor, which was owner driven due to the special equipment needed for the program.

\subsubsection{The Development of the BIM Package and using it in Practice}

The Cinematic Arts project was the first set of buildings on campus with the use of BIM practices. The donor had just finished a project that was very successful after utilizing BIM and came forward to USC wanting to utilize it on this project. When the Cinematic Arts project started, the BIM guidelines were not part of the contract documents; but when the project got to Phase III, it played an integral part of the contract. The document "defines the Design and Construction scope of work and deliverables for using Building Information Modeling (BIM) on new USC construction projects, major renovations and other projects as required by USC, based on a Design Bid Build form of contract." ${ }^{\not 2}$ The BIM guidelines packet will be used for all of the new buildings being built on campus that will be utilizing the COBie system. ${ }^{43}$

This BIM standards document came into conception during the first phase of the project, before Matt Construction joined the collaboration. It began with getting the

${ }^{42}$ Building Information Modeling (BIM) Guidelines. PDF. University of Southern California, April 18, 2012.

${ }^{43}$ Jesus Fuentes (USC Cinematic Arts Project Manager). Telephone interview by author. December 2, 2014. 
Facilities Management involved. None of the FM had been involved early in a building project before.

Next, the owner made a design decision and didn't want any expansion joints showing on the exterior of the building. The Architect then challenged the Structural Engineer to design a system that would accomplish invisible expansion joints. Essentially, designing in Tekla, the Structural Engineer came up with an exoskeleton concept with shear walls and a flexible diaphragm in the middle of the structure. Raymod Kahl, the Architect for the project, states that the Structural Engineer was enthusiastic about being able to model the system. He went even farther, designing all of the reinforcement forms. The reinforcing bars package was created, which eliminated a shop drawing process, and greenlighted fabrication. It was then asked by the Facilities Management staff if the same modeling concept could be incorporated for the mechanical system. When the model was all done, it was handed over to the Contractor, and passed on to Subcontractors. If the Subcontractor found a comparable unit to use instead of what was specified, it would be incorporated into the model and updated for as-builts and future use.

When the first building of Phase III was going through closeout, since there was enough room on the server, it was decided that all of the equipment in the model would have a hyperlink associated to their respective manual. The software developed, COBie, for Facilities Management allowed for continuous monitoring of the mechanical 
equipment, and would alert the team if there was an issue with the equipment. This was important for the goal of the building's 100 year lifespan. ${ }^{44}$

\subsubsection{BIM in Use}

As mentioned earlier, USC now has a document for BIM expectations for any new buildings that are to be built on campus, which was created as a result of the successful use of BIM throughout the first two phases of the Cinematic Arts project. This is a very developed document as to what to include within the project. And although, in more recent projects, the document has been scaled back a bit or altered to fit the particular project. Although the packet states it is for Design Bid Build, it is used as a guideline for this project, and was treated as part of the contract documents for the Designers and Contractors. The document includes a statement with BIM and collaboration:

"Establishing a collaborative environment and collaborative use of the BIMs during the design and construction process where the designers, contractor, subcontractor and owner work together with a proactive approach to issue resolution."45

The guidelines stated that the architect and the general contractor must submit a BIM Execution Plan, or a BEP, which describes processes and procedures that are placed within their discipline for deliverables. This document has detailed instructions ranging from naming files and color conventions of trades within Navis Works models, all the way to what Level of Detail the model should be and the layout for COBie systems.

44 “Better Designs. Smarter Operations," Autodesk, 2010, accessed May 15, 2015, http://static-dc.autodesk.net/content/dam/autodesk/www/industries/architectureengineering-construction/building-owner-operations-management/Docs/usc-v7.pdf.

${ }^{45}$ Building Information Modeling (BIM) Guidelines. PDF. University of Southern California, April 18, 2012. 


\subsubsection{BIM Usage Examples:}

Unlike typical projects, it was the donor that requested BIM be used on the project. According to the Owner's Representative, Mandeep, it seems that the Designer and the Contractor were a bit fearful of using BIM on the project, but took on the challenge. With the well-developed working models from the design team, it really helped the Subcontractors develop as-builts, and prevent any clashes from occurring in the field.

The modeling became a bit difficult when there were scopes of work that were not in the control of Matt Construction. There were items that were contracted by the owner, such as the audio/visual systems. This posed a challenge, when trying to incorporate the audio visual (AV) 3D model into the central model, mostly because the AV was not done in Revit like the rest of the models. All of the data was known, but the different modeling program did not interface well with the programs being used by Matt Construction. USC has since remedied this in their BIM guidelines by requiring all AV equipment models be submitted in their own Revit file.

The model was updated on a weekly basis. Matt Construction was given the model, and the Subcontractors were able to make the changes necessary on a weekly basis. If there were additional design changes (bulletin or addendum), those would be coordinated so there wouldn't be an impact to the construction schedule. The live model was fully controlled by the Architect, but the Subcontractors and the GC would provide updates to the model, and the Architect would merge and update the model that was provided on a weekly basis.

When the building of Phase 1 began, the schedule was set to have the building open in between semesters. The process got behind, and the finish date was changed to spring 
break. Even that was an aggressive date. Producing a model and working with the contractor to understand what was needed, the original schedule of Phase I was met. With the same system implemented in Phase 2, the building finished one semester ahead of schedule, and Phase 3 was delivered early as well.

\subsubsection{Lessons to take away}

If the process had to be done over again, Mandeep said that he would have liked to utilize BIM earlier in the project. One way this could have been done was by using building massing models to visualize where the building might fit best on the campus.

\subsection{The projects without BIM}

There isn't a case study of a project that doesn't use BIM in this chapter. But imagine if BIM were not used in these projects at all, or even a portion of the projects. Below are some possibilities of what might have happened had BIM not been implemented into the projects.

\subsubsection{Instance 1: If owner had not requested BIM being used}

It was requested by the owners for both the Airport and USC jobs that BIM be used on the project. If it were not requested to have BIM implemented per the owner, two things may have happened: either BIM would not have been implemented by any of the parties, or one of the parties would have implemented it, but most likely as a tool to help the project move forward for themselves. This becomes a slippery slope, because if BIM was not implemented at all, many discoveries would not have been made such as the schedule reduction for USC or the pedestrian bridge not being able to be placed due to swing radius. Even if it were implemented by the Designers or the Contractor for use within the firm, this would break the idea of being a collaboration. Through BIM being 
written into the contract, the parties were in essence, forced into working together to make things work smoothly. If one party is doing their own model, they wouldn't be required to share it with other members of the project.

\subsubsection{Instance 2: If the Designer didn't model}

The designers were given the challenge for the USC project to not have expansion joints showing. BIM is a tool that allows the designer to essentially build a model without the inefficiency of re-building a physical model. With the computer, you can simply modify, solving the puzzles as they come along, before experiencing the problems out in the field. So in the case of the structural joints being hidden, the team chose to model rather than build multiple mock-ups to figure out how it will work. Not only can the model be visualized, it can be digitally tested to see if it will work, all without making a mess.

\subsubsection{Instance 3: If the Contractor didn't get involved}

BIM had been used on the San Diego Airport Project for existing underground utilities. If the use of BIM hadn't been implemented, the Subcontractor would have started to dig and lay pipe, only to find that there would be a conflict at the end. If the contractor hadn't pre-planned, there would have been a cost increase to the project.

\subsubsection{Conclusion}

There are multiple instances that can prove that BIM was useful on these projects, and even proved some BIM practices could be eliminated during the process. What is groundbreaking about these two projects, is the Owners wanted BIM to be implemented. Getting the Owner to understand that BIM is a tool that can potentially save money by 
solving problems is important, and getting them to grasp what services they are actually paying for.

Industry standards have been implemented for how detailed the model is, but it seems that there isn't an industry standard for how BIM should be implemented into an IPD project. Perhaps a range of guidelines with the different levels of BIM utilized on a project should be put into place. 


\section{CHAPTER 5}

\section{CONTRACT DOCUMENTS FOR IPD AND BIM}

\subsection{What is a Construction Contract?}

A contract defines what should be accomplished within the project, and it is important that it is enforced. When an agreement is in writing, it is easier to enforce. "Typically the process by which contracting parties make an agreement involves communications, oral and written, that culminate with one party making an offer and the other party accepting it."46 The state of California Civil Code Section 1622 states: "All contracts may be oral, except such as are specially required by statute to be in writing." ${ }^{47}$ A contract can legally be verbal, but typically if it is a verbal agreement, it is followed up with a written document to confirm the agreement to prevent any disputes that may occur at a later date. The world of building has grown accustomed to having everything in writing, and preferably everything upfront. "The principal function of enforcing contracts in the commercial world is to encourage economic exchanges that lead to economic efficiency and greater productivity. This is accomplished by protecting the reasonable expectations of contracting parties that each will perform as promised."48 If a contract is not honored or followed, then certain aspects of the project may have been implemented incorrectly.

${ }^{46}$ Justin Sweet and Marc M. Schneier, "Contracts: From Formation to Breach," in Legal Aspects of Architecture, Engineering and the Construction Process (9th ed. Stamford, Conn.: Cengage Learning, 2013), 44.

${ }^{47}$ CA Codes (civ:) s.v. "Civil Code Section 1619-1633," accessed July 8, 2015, http://www.leginfo.ca.gov/cgi-bin/displaycode?section=civ\&group=01001 $\underline{02000 \& \text { file }=1619-1633 .}$

${ }^{48}$ Justin Sweet and Marc M. Schneier, "Project Organization, Pricing, and Delivery Methods," in Legal Aspects of Architecture, Engineering and the Construction Process (9th ed. Stamford, Conn.: Cengage Learning, 2013), 43. 
Typical documents included in the construction process are standard documents such as Consensus DOCs or AIA forms, Specifications, and Plans. The construction documents often cross reference each other in order to allow for full understanding of what is supposed to be built. Without these documents, the construction world would be left to the best guesses of Constructors who may not fulfill the vision of the Owner and Designer. Although the BIM Implementation Plan or BIM Execution Plan may be a construction document, it may not be considered a contract document; therefore it is vital that a project's BIM requirements be implemented into the contract.

\subsection{Design and Constructability Contract}

"The primary purpose of construction drawings [documents] is to communicate the intended elements, systems, and relationships of materials, equipment, and assemblies to the contraction in the construction of the facility." 49 This is true for all project delivery methods, but very important in the IPD contract method. However, not all construction documents are contract documents; the collaboration of the team should start from conception of the project. As mentioned in the "BIM and the Construction Management Body of Knowledge" chapter of Product Lifecycle Management for Society, there are three value components: Designability, Constructability, and Contractibility to the use of BIM. $^{50}$

\footnotetext{
${ }^{49}$ William Mincks and Hal Johnston, "Use of Construction Documents on the Jobsite," Construction Jobsite Management (3rd ed. Cengage Learning, 2010), 45.

${ }^{50}$ Mehmet Yalcinkaya and David Arditi, "Building Information Modeling (BIM) and the Construction Management Body of Knowledge," Product Lifecycle Management for Society: 10th IFIP WG 5.1 International Conference, PLM 2013, Nantes, France, July 610, 2013: Proceedings, Vol. 409 (IFIP Advances in Information and Communication Technology, Springer Berlin Heidelberg, 2013) 619-29.
} 


\subsubsection{Designability}

Designability focuses on the project design overall. "BIM and the Construction Management Body of Knowledge" states that it allows designers to respect the required specifications, and that the specifications must be followed. This allows all of the parties, not just the Designers, to see what the building will actually look like. Oftentimes, this will lead to redesigns for the building if the Owner or the Designer realize the design is not what they imagined in their minds. This actually happened on the San Diego International Airport project where a design decision was made based on a model from three different choices.

\subsubsection{Constructability}

Constructability brings in value to the building through materials, details, means, methods and techniques. This process allows more than just the GC to virtually review conflicts. An issue was brought up specifically with the San Diego International Airport when doing the rerouting of underground utilities. There was a need for accuracy with tolerances for making a connection in a model, where in a $2 \mathrm{D}$ drawing there is room for more mistakes. Once the initial model is done, it allows the Owner, Designer, and Contractor to sit down and discuss how to mitigate issues, change means and methods as needed, and change materials if necessary. Another example of this is the USC Cinematic Arts project, when the owner wanted to implement a building that would not show any of the expansion joints on the exterior of the building. This could be done by 
working out the system in Tekla and creating a flexible diaphragm, eliminating the expansion joints and having a smooth, uninterrupted wall. ${ }^{51}$

\subsubsection{Contractibility}

Most related to this chapter is Contractibility and how BIM increases the value through different contract options, assignments and procedures. One thing that both of the projects have in common is that BIM was implemented into the contract, or had its own contract document, despite being different forms of project delivery. The contract helped make a difference in the projects.

Throughout the different phases of the USC Cinematic Arts Project, the BIM implementation plan became more sophisticated, and by the time the last phase was out to bid, it was clear what the owner wanted and implemented it into the construction documents. Through the use of this tool, the last phase was handed over early.

\subsection{Legal Issues of BIM}

"Widespread adoption of BIM by the construction industry faces serious legal impediments. BIM project delivery in many ways erases the distinction among designer, builder, and component supplier."52 Blurring the lines between the different parties tailors to the IPD contract, making liability for the model equal. But as a team, roles need to be defined and what will be included for the use of BIM.

As stated by Gregory Gangitano, a Legal Consultant at Gordon \& Rees LLP, the following steps need to be specified when sitting down to draft a contract: what will be

\footnotetext{
${ }^{51}$ Jesus Fuentes (USC Cinematic Arts Project Manager), Telephone interview by author, December 2, 2014.

52 Justin Sweet and Marc M. Schneier, "Project Organization, Pricing, and Delivery Methods," In Legal Aspects of Architecture, Engineering and the Construction Process, 9th ed. (Stamford, Conn.: Cengage Learning, 2013), 44.
} 
implemented in the model, the notification protocol for any mistakes or changes needed in the model, how the issues will be resolved, and how they will be utilized as updated construction documents.

One of the contract types that Sundt Construction covers is Design Build, a form of IPD. Like the San Diego Airport, BIM is typically a contract with the owner. According to Dan Russel, Director of Construction Technology at Sundt Construction, when BIM is implemented into a Design Build project, Sundt has a template of typical language that is put in place between the Design Build parties. Then a BIM execution plan is put in place. Sundt has found this language to be successful between the major acting parties.

Blurring the lines between the parties also blurs the lines in traditional contract format. These contract forms may also sound like they are against integration between all of the parties, but they are implemented as a safety net, in case there is a situation where teams run into legal issues.

\subsection{AIA Contract Documents}

There are many procurement documents for the delivery of projects for an owner in the United States. A very common set of contract documents is through the American Institute of Architects, AIA. The goal of these documents created by the AIA are to "define the relationships and terms involved in design and construction projects." 53 The AIA was the first to implement a set of guidelines for Integrated Project Delivery method, as the demand in the design and construction industry has changed over time.

${ }^{53}$ About Contract Documents, s.v. "Contract Documents," accessed March 15, 2016, http://www.aia.org/contractdocs/about/index.htm. 


\subsubsection{Integrated Project Delivery: A Guide}

The guide discusses many aspects of the Integrated Project Delivery method such as: setting up an IPD project, delivering under an IPD method, and multi-party agreements. The guide also claims that "a digital, three-dimensional model linked to a database of project information, is one of the most powerful tools supporting IPD." ${ }^{54}$ BIM is a technology driven tool, and is not a delivery method. The guide compares the technology and communication used in "Traditional Project Delivery," which uses "paper based, 2dimensional" documents, and IPD, which is digitally based and uses virtual construction and BIM. It is important that the project delivery team to have a clear understanding as to how the model will be developed, accessed, used, how the information will be exchanged, and what level of detail the models will be.

\subsubsection{AIA Digital Practice Documents}

The American Institute of Architects, AIA, created a new section of contracts for Digital Practice in 2007. Typically AIA contracts are revised every ten years, but because of the digital data used in the industry are continuously changing, it is not as useful to revise in such large time spans. Below is a table of different documents utilized in AIA BIM.

Expectations need to be set by all of the parties, different protocols decided upon, and how both will be governed and at what level of detail items need to be. This is a very important process, because it gets the team to communicate and have an overall understanding of the end goals of the BIM model in an IPD setting.

\footnotetext{
${ }^{54}$ American Institute of Architects, s.v. "Integrated Project Delivery: A Guide," accessed June 07, 2015, http://www.aia.org/groups/aia/documents/pdf/aiab083423.pdf.
} 


\begin{tabular}{|c|c|}
\hline \multicolumn{2}{|c|}{ AIA Documents } \\
\hline AIA C 106 & $\begin{array}{l}\text { A licensing agreement between two parties who otherwise have no existing } \\
\text { licensing agreement for the use and transmission of digital data, including } \\
\text { instruments of service. AIA Document C106-2013 defines digital data as } \\
\text { information, communications, drawings, or designs created or stored for a } \\
\text { specific project in digital form. C106 allows one party to (1) grant another } \\
\text { party a limited non-exclusive license to use digital data on a specific } \\
\text { project, (2) set forth procedures for transmitting the digital data, and (3) } \\
\text { place restrictions on the license granted. In addition, C106 allows the party } \\
\text { transmitting digital data to collect a licensing fee for the recipient's use of } \\
\text { the digital data. }\end{array}$ \\
\hline AIA E 203 & $\begin{array}{l}\text { Version } 2013 \text { is not a stand-alone document, but must be attached as an } \\
\text { exhibit to an existing agreement, such as the AIA Document B101TM_-2007, } \\
\text { Standard Form of Agreement Between Owner and Architect, or A101TM_- } \\
\text { 2007, Agreement Between Owner and Contractor. Its purpose is to establish } \\
\text { the parties' expectations for the use of digital data and building information } \\
\text { modeling (BIM) on the project and provide a process for developing the } \\
\text { detailed protocols and procedures that will govern the development, use, } \\
\text { transmission and exchange of digital data and BIM on the project. Once } \\
\text { agreed to, E203-2013 states that the relevant protocols and procedures will } \\
\text { be set forth in AIA Documents G201 } \\
\text { Form and G202013, Project Digital Data Protocol } \\
\text { Form. E203 does not create a separate license to use digital data because } \\
\text { AIA documents for design or construction, to which E203 would be } \\
\text { attached, already include those provisions. Parties not covered under such } \\
\text { agreements should consider executing AIA Document C106 } 6^{\mathrm{TM}}-2013 \text {, } \\
\text { Digital Data Licensing Agreement. }\end{array}$ \\
\hline $\begin{array}{l}\text { AIA G } \\
201\end{array}$ & $\begin{array}{l}\text { Version } 2013 \text { is a form that is coordinated for use with AIA Document } \\
\text { E203 } \\
\text { Exh-2013, Building Information Modeling and Digital Data Protocol } \\
\text { procedures that will govern the transmission, use and exchange of digital } \\
\text { data on a project, such as electronic project communications, submittals, } \\
\text { contract documents and payment documents. G201-2013 is not designed to } \\
\text { address Building Information Modeling protocols and procedures, which is } \\
\text { the purpose of AIA Document G202TM_2013, Project Building Information } \\
\text { Modeling Protocol Form. }\end{array}$ \\
\hline $\begin{array}{l}\text { AIA G } \\
202\end{array}$ & $\begin{array}{l}\text { Version } 2013 \text { is a form that is coordinated for use with AIA Document } \\
\text { E203 } \\
\text { Exh-2013, Building Information Modeling and Digital Data Protocol } \\
\text { procedures that will govern the development, transmission, use and }\end{array}$ \\
\hline
\end{tabular}




\begin{tabular}{|l|l|}
\hline $\begin{array}{l}\text { exchange of building information models on a project. It establishes the } \\
\text { requirements for model content at five levels of development, and the } \\
\text { authorized uses of the model content at each level of development. Through } \\
\text { a table completed for each project, AIA Document G202-2013 assigns } \\
\text { authorship of each model element by project milestone. G202 defines the } \\
\text { extent to which model users may rely on model content, clarifies model } \\
\text { ownership, and sets forth building information modeling standards and file } \\
\text { formats. }\end{array}$ \\
\hline
\end{tabular}

Figure 17: Digital Practice Documents ${ }^{55}$

\subsection{AGC Consensus Docs}

The Associated General Contractors (AGC) Consensus Docs are produced by construction associations that represent Design Professionals, Owners, Constructors, Subcontractors, and Sureties. This group wanted to incorporate best practices in the construction industry for standard construction contracts that fairly allocate risks to the party that will be in the position to manage and control those risks. ${ }^{56}$

\section{Consensus Docs}

CD $300 \quad$ A tri-party agreement, the Owner, Designer and Constructor sign the agreement at the inception of the project, binding them to collaborate in the planning, design, development and construction of the project and a sharing of project risks and rewards different than traditional project. Lean construction principles underlying design and construction are used to drive out waste. Representatives of the three parties manage the project through consensus decision-making. While the designer retains ultimate design responsibility in accordance with state licensing laws, the constructor and specialty Contractors and Suppliers participate in the development of the project design. There is no guaranteed maximum price

55 "Contract Documents." AIA, accessed July 2015, http://www.aia.org/contractdocs/AIAS076721.

${ }^{56}$ Consensus Docs Guidebook, s.v. Accessed March 15, 2016, http://www.consensusdocs.org/Resource_FileManager/All_Associations_Guidebook.pdf 


\begin{tabular}{|l|l|}
\hline $\begin{array}{l}\text { CD } \\
\text { Addendum }\end{array}$ & $\begin{array}{l}\text { The 301 BIM Addendum should be used where the Owner, lead design } \\
\text { professional, lead construction professional, and major subcontractors and } \\
\text { suppliers are willing to commit to model the project design and } \\
\text { construction media using three-dimensional design or modeling software } \\
\text { with demonstrated interoperability, so as to eliminate the need for } \\
\text { conversion of two-dimensional design and construction documents into } \\
\text { three-dimensional virtual models. The 301 BIM Addendum can be used } \\
\text { whether or not any Design Model is considered a Contract Document. }\end{array}$ \\
\hline
\end{tabular}

Figure 18: Consensus Documents ${ }^{57}$

The Consensus Documents were the first standard IPD document published in the US. Consensus Doc 300 follows the model shown in Figure 3 in Chapter 2 where the Owner, Designer, and Constructor all sign the same agreement. The goal of this document is to make decisions in a way that increases project efficiency. ${ }^{58}$

Addendum 301 is an addition to CD 300 to address the use of BIM. Each party that contributes or accesses to the model, is responsible for risk. There is an exception to this rule: "each party agrees to waive claims against the other parties to the Governing Contract for consequential damages arising out of or relating to the use of or access to, a Model." 59 This helps with the accuracy of the project. If the model is not accurately shown, then there could be a conflict within the building. It is important that the most

57 Ibid.

${ }^{58}$ Concensus Docs Contract Catalog, s.v. "Contract Catalog," accessed March 15, 2016, https://www.consensusdocs.org/catalog/collaborative.

${ }^{59}$ Contract Forms and Drafting/Building Information Modeling, s.v. "Consensus DOCS 301 BIM Addendum," by Lowe, Richard H., and Jason M. Muncey, accessed May 2015, https://www.consensusdocs.org/News/Download/d2458cb3-5ba4-4e2d-bb1d9fb400cfd2fc?name=ABA-Winter-09-ConsensusDOCS-301-BIM-Addendum-Lowe-andMuncey.pdf. 
recent model is shared with everyone who is included on the project for the most accurate work to be done.

The Consensus Docs 301 differs from the AIA documents listed above, and does require a BIM Execution Plan, whereas the AIA documents do not. The BIM Execution Plan would ideally lay out the extent of the scope of services to be provided. It also states that another meeting may be called if there is to be any modification to the BIM Execution Plan. This requires all parties to sit down and discuss the goals that they have for the project and how they can accomplish them with the use of BIM.

\section{BIM Execution Plan Options}

Each contributor represents that the dimensions in its Contribution to a Model are accurate and take precedence over the dimensions called out in the Drawings or inferred from the Drawings. Details and components that are not represented in a Contribution to a Model must be retrieved from the Drawings.

Each Contributor represents that the dimensions in its Contribution to a Model are accurate to the extent that the BIM Execution Plan specifies dimensions to be accurate, and all other dimensions must be retrieved from the Drawings.

Contributors make no representation with respect to the dimensional accuracy of the Contributor's Contribution to a Model. A Model can be used for reference only and all dimensions must be retrieved from the Drawings.

Specify own level of reliance that Project Participants may place on Contributors.

Figure 19: BIM Execution Plan Options 60

${ }^{60}$ Ibid. 
The BIM Addendum 301 has three check boxes with which the parties can decide what BIM Execution Plan best fits the project as shown in the figure below.

Section 4.3 of Addendum 301 allows for additional elements to be added to the BIM Execution Plan for project specific needs. Each option in the figure below is less stringent than the last.

\subsection{US Army Corp of Engineers}

The US Army Corp of Engineers have a Building Information Modeling Requirements document for Design-Build projects that do not have a specific BIM format spelled out. This document defines the minimum modeling requirements and is to be included with the Project Execution Plan for any project with USACE. Originally, the document left interpretation very open, so deliverables submitted by contractors were inconsistent. The USACE has three major documents included.

The first document is the contract language that is normally included in the Request for Proposal (RFP), the second is the Execution Plan (PxP) template that must be used in association with the last and newest document Minimum Modeling Matrix (M3).

\subsubsection{PxP}

Like the Consensus Docs, the USACE requires a BIM Execution Plan (PxP). PxP was adapted from the National BIM Standards (NBIMS) which, when completed properly, should define uses of BIM on the project. It outlines how BIM is executed in the project during "design authoring, design reviews, 3D coordination, and record modeling."61 Design authoring is when the designers are in their beginning and intermediate design phases. Design review is towards the final stages of design and constructability review.

${ }^{61}$ US Army Corps of Engineers. USACE BIM Project Execution Plan Version 2.1. 
3D coordination is where all of the trades, mostly MEP, coordinate the systems to work within the building. Lastly, record modeling is for as-built and turn over documents.

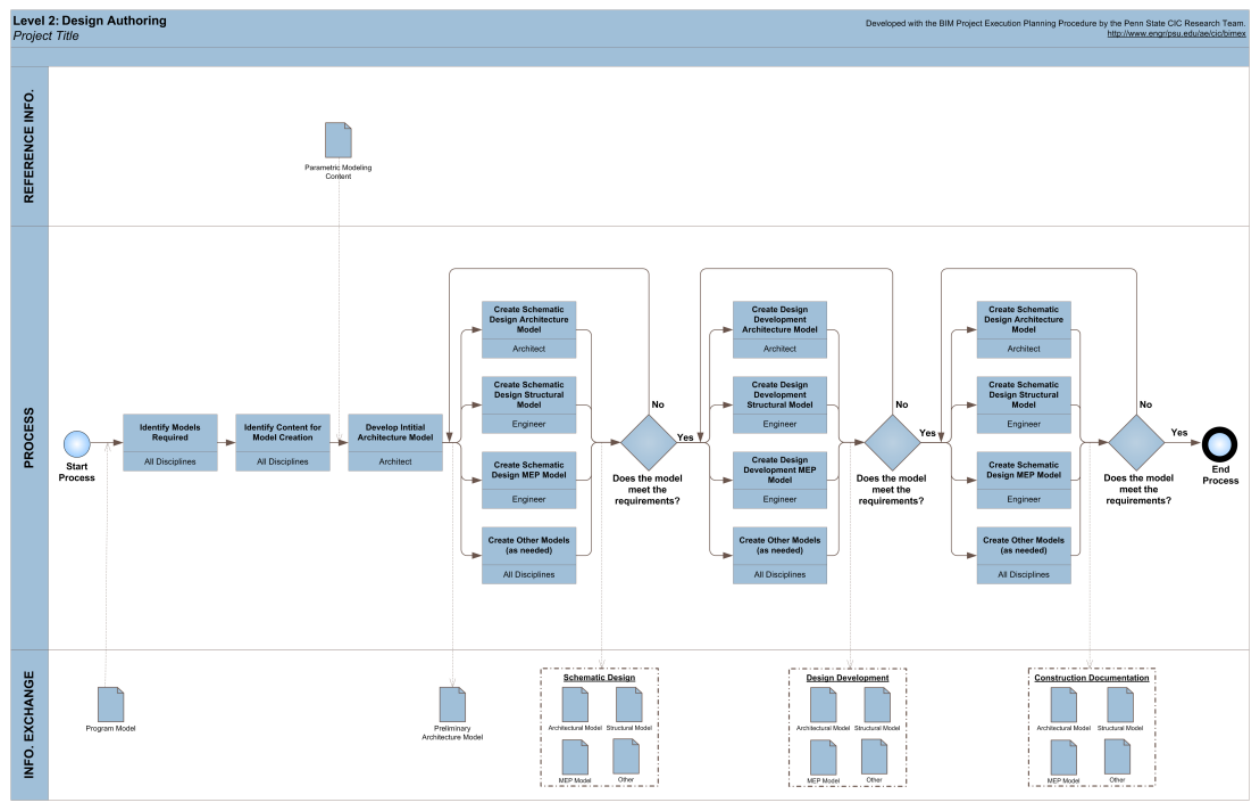

Figure 20: USACE PXP Template ${ }^{62}$

Through the process of the BIM execution plan, there needs to be communication between the GC and the Subcontractor and establish contractual agreements for a successful project. This document allows the group to sit down and spell out what the objectives are for the use of BIM on a project, and then split up who is in charge of the different elements. A BIM process map is then created for a visual for all BIM uses. See example above in Figure 20.

Figure 21 is a spreadsheet showing segments of the project broken down in the USACE PXP template. All of the boxes represent what can be covered in the PXP in order to maximize project value. The red cells in the spreadsheet are elements required by

${ }^{62}$ US Army Corps of Engineers. USACE PXP Template. 
USACE. This may give a good idea for what should be used, but does not open the matter up for discussion.

\begin{tabular}{|c|c|c|c|c|c|}
\hline PROGRAMMING & $\mathbf{x}$ & DESIGN AUTHORING & & SITE UTILIZATION PLANNING & BUILDING SYSTEM ANALYSIS \\
\hline \multirow[t]{10}{*}{ SITE ANALYSIS } & $\mathbf{X}$ & PROGRESS REVIEWS & & $\begin{array}{c}\text { CONSTRUCTION SYSTEM } \\
\text { DESIGN }\end{array}$ & ASSET MANAGEMENT \\
\hline & $\mathbf{x}$ & $\begin{array}{l}\text { INTERFERENCE MANAGEMENT } \\
\text { (3D COORDINATION) }\end{array}$ & $\mathbf{X}$ & $\begin{array}{l}\text { INTERFERENCE } \\
\text { MANAGEMENT } \\
\text { (3D COORDINATION) }\end{array}$ & $\begin{array}{l}\text { SPACE MANAGEMENT / } \\
\text { TRACKING }\end{array}$ \\
\hline & & STRUCTURAL ANALYSIS & & DIGITAL FABRICATION & DISASTER PLANNING \\
\hline & & LIGHTING ANALYSIS & & 3D CONTROL AND PLANNING & \\
\hline & & ENERGY ANALYSIS & $\mathbf{x}$ & RECORD MODELING & $\begin{array}{l}\text { OPERATION \& MAINTENANCE } \\
\text { RECORD MODELING }\end{array}$ \\
\hline & & PROGRAM VALIDATION & & FIELD / MATERIAL TRACKING & \\
\hline & & MECHANICAL ANALYSIS & & DIGITAL LAYOUT & \\
\hline & & OTHER ENG. ANALYSIS & & & \\
\hline & & $\begin{array}{l}\text { SUSTAINABILITY (LEED) } \\
\text { EVALUATION }\end{array}$ & & & \\
\hline & & CODE VALIDATION & & & \\
\hline PHASE PLANNING (4D) & & $\begin{array}{l}\text { PRELIMINARY CONSTRUCTION } \\
\text { SCHEDULING (4D) }\end{array}$ & & $\begin{array}{c}\text { CONSTRUCTION SCHEDULING } \\
\text { (4D) }\end{array}$ & $\begin{array}{l}\text { BUILDING MAINTENANCE } \\
\text { SCHEDULING (4D) }\end{array}$ \\
\hline COST ESTIMATION (5D) & & COST ESTIMATION (5D) & & COST ESTIMATION (5D) & COST ESTIMATION (5D) \\
\hline $\begin{array}{l}\text { EXISTING CONDITIONS } \\
\text { MODELING }\end{array}$ & & EXISTING CONDITIONS MODELING & & $\begin{array}{c}\text { EXISTING CONDITIONS } \\
\text { MODELING }\end{array}$ & $\begin{array}{l}\text { EXISTING CONDITIONS } \\
\text { MODELING }\end{array}$ \\
\hline $\begin{array}{c}\text { CONSTRUCTION } \\
\text { OPERATIONS BUILDING } \\
\text { INFORMATION EXCHANGE } \\
\text { (COBie) }\end{array}$ & & $\begin{array}{l}\text { CONSTRUCTION OPERATIONS } \\
\text { BUILDING INFORMATION } \\
\text { EXCHANGE (COBie) }\end{array}$ & & $\begin{array}{c}\text { CONSTRUCTION OPERATIONS } \\
\text { BUILDING INFORMATION } \\
\text { EXCHANGE (COBie) }\end{array}$ & $\begin{array}{l}\text { CONSTRUCTION OPERATIONS } \\
\text { BUILDING INFORMATION } \\
\text { EXCHANGE (COBie) }\end{array}$ \\
\hline
\end{tabular}

Figure 21: BIM Uses ${ }^{63}$

\subsubsection{Minimum Modeling Matrix (M3)}

The Minimum Modeling Matrix (M3) is a newly released document: a spreadsheet that expresses the detail of required modeling scope with definitions to go with it to help clarify any questions the contractor might have. One of these items is the Level of Development Definitions which defines accuracy in the model, very similar to the Levels of Detail already covered in previous chapters.

Based on the Level of Development breakdown below, there is another chart for element grade definitions. This allows for the elements to be presented in various

63 Ibid. 
formats. "In practice, it has been proven that there are certain elements for which there is a greater benefit in providing 3-dimensional representation, while others drafting or representation in the form of narratives is sufficient for a particular deliverable." ${ }^{\prime 64}$ Below is a rubric of the grade definitions used by USACE in the M3. Between all of the formats that are covered by this matrix (OmniClass, Uniformat, and Masterformat), it covers the basis of getting all of the information needed to turn the materials over to the owner at the end of the project.

\begin{tabular}{|c|l|}
\hline LOD & Definition \\
\hline $\mathbf{1 0 0}$ & $\begin{array}{l}\text { Refer to the specific child element for appropriate LOD. (Used for categories that have } \\
\text { multiple sub-elements for which varying LOD apply.) }\end{array}$ \\
\hline $\mathbf{2 0 0}$ & $\begin{array}{l}\text { Model Elements indicative of area, height, volume, location, and orientation may be } \\
\text { modeled geometrically or represented by other data (i.e., a pump would be a cube.) }\end{array}$ \\
\hline $\mathbf{3 0 0}$ & $\begin{array}{l}\text { Model Elements are modeled as generalized systems or assemblies with approximate } \\
\text { be attached to Model Elements (i.e., a pump would be a generic pump of approximate } \\
\text { size.) }\end{array}$ \\
\hline $\begin{array}{l}\text { Model Elements are modeled as specific assemblies accurate in terms of quantity, size, } \\
\text { shape, location, and orientation. Non-geometric information may also be attached to } \\
\text { Model Elements. Accurate to the degree dimensioned or indicated on contract } \\
\text { documents (i.e., a pump would be a generic pump of accurate size complete with } \\
\text { connections and clearances for a complete system.) }\end{array}$ \\
\hline
\end{tabular}

Figure 22: LOD Definitions ${ }^{65}$

${ }^{64}$ US Army Corps of Engineers. USACE M3 Template.

${ }^{65}$ US Army Corps of Engineers. USACE BIM Project Execution Plan Version 2.1. 


\begin{tabular}{|c|l|}
\hline Grade & Description \\
\hline A & 3D + Facility Data \\
\hline B & 2D + Facility Data \\
\hline C & 2D Only (Drafting, linework, text, and or part of an assembly) \\
\hline+ & Original Grade (A, B, or C) adjusted for contract changes and field conditions. \\
\hline- & Not included in or tied to the model (however is still required in the deliverable) \\
\hline & $\begin{array}{l}\text { Refer to the specific child element for appropriate Grade. (Used for categories } \\
\text { that have multiple sub-elements for which varying Grades apply.) }\end{array}$ \\
\hline
\end{tabular}

Figure 23: M3 Grading Rubric ${ }^{66}$

The two charts in the M3 also allows for Quality Control Checks within the team to assure quality of the final product. This is necessary for collaboration, to make sure that all parties are holding each other accountable. Some of the items listed in the Figure 23 above are key to helping the project succeed. For example, if a version update check is not performed, there might have to be rework on project elements. A version of a model may not be able to be opened in an older version of the program. With everyone on the same page for programs, it might prevent someone from having to go back and model in the older version in order for others to see the model.

It is important to have these checklists to distinguish whether the model will be turned over to the owner or if it will be for in-house purposes. Even if it is used for internal purposes, it is important to lay out expectations of the team.

In an IPD project where everyone is working as a team, everyone is liable for what was missed. The model is essentially a snapshot of what is discussed and implemented. If an item was modeled and was later neglected in the building, then the Subcontractor would be at fault and would be accountable for any extra costs.

66 Ibid. 


\subsection{Conclusion}

These few contract document options do have the ideas of IPD, documenting, and communication in mind, but they are not complete individually as standalone documents. If there was a way to combine all of them, and add a little more, it would make it a stronger document for the implementation of BIM into a contract and integrated project. The next chapter will consist of a template to provide a possible solution to creating a supplementary document for BIM implementation that has elements of all of the documents above and more to spark a conversation between the integrated parties. 


\section{CHAPTER 6}

\section{A NEW TYPE OF BIM CONTRACT}

\subsection{Merging IPD Contract Formats}

It has been established that no one building project is the same, which eludes to every building contract to be different, whether it be what documents are included in the contract down to the language that is used. In this chapter, the implementation of BIM into a contract will be discussed.

"A note on Building Information Modeling: It is understood that integrated project delivery and Building Information Modeling (BIM) are different concepts - the first is a process and the second a tool. Certainly integrated projects are done without BIM and BIM is used in non-integrated processes. However, the full potential benefits of both IPD and BIM are achieved only when they are used together."67 This chapter will suggest an approach to creating contracts for the implementation of BIM with the influence of the various documents that were mentioned in the previous chapter for an IPD project. Although this will not include contract legal language, it will be a guideline and a conversation piece that would help segue into what might be included in the contract documents.

\subsection{Building the Contract}

This contract type approach will be similar to that of Sundt Construction's unique approach to writing contracts. Sundt has created a database with the standard language of a contract with subcontractors, where one can choose all of the items needed in the

${ }^{67}$ American Institute of America California Council, s.v. "Integrated Project Delivery - A Working Definition," accessed June 15, 2015, https://www.dir.ca.gov/das/hcc/WorkingDefinition.pdf. 
contract. Much of the same language is used on the various types of contracts, and adjust language according to what contract type is decided upon: Design-Build, CM at Risk (CMAR), or Design-Bid-Build. An example from Sundt's BIM scope documents discussing diagrammatic drawings and general arrangements of systems:

"Where the Drawings are diagrammatic, showing only the general arrangement of the systems, subcontractor shall have responsibility for the fitting of materials and equipment to other parts of the equipment and structure, and to make adjustments as necessary or required to resolve space problems, preserve service room, and avoid architectural and structural elements and the work of other trades. "68

After deciding what contract type is being used, the items are dragged over from the database and adjusted as needed. This process is used with standard contract language, but what if this idea was used for a BIM implementation portion of the IPD contract? There are many ways to incorporate BIM into a project, this will allow the parties to decide what they want to include in their Integrated Project Delivery BIM contract and at what stages the process will be implemented.

\subsubsection{Implementing a Model?}

First, it is important to distinguish if you are going to use the model as a contract document or not. The contract could be written in two ways: the contract could say that BIM needs to be implemented as a deliverable or the model could be used as an element of the contract. If it is required in the contract, this is just a written requirement saying that it needs to be instated. If the model was used as part of the contract, it would have the same amount of importance as the plans and specifications. Just like plans in a traditional project, the model would be a set of guidelines for builders.

${ }^{68}$ Sundt Construction, Inc. BIM Requirements. 
If it is chosen not to be included in the contract, a project team may choose to instate utilization and practices of a model even if they are not included in the contract. Though it may not be required in the contract it is important to let everyone know that it will be used whether it is to be included in the qualifications packet for the Contractor, or in the contract agreements from the Owner to Designer.

\subsubsection{Model Implementation Contract Checklist}

Next, decide what part of the IPD process BIM should be instated: conceptualization, criteria design, detailed design, implementation documents, agency coordination, construction, and closeout. Through the checklist provided below, the IPD project team can have a discussion as to what should be implemented into the model, and how it will be implemented. "In an integrated project, all team members provide whatever input they can to all aspects of the project" 69

\subsubsection{Implement Checklist and Model into Project}

Based on what is decided through the discussion of the checklist, a plethora of scenarios arise: it will help lead the team to what should be done. Whether it only includes certain parts of the model in the project, or all elements. It can also help determine, if the BIM model will be used as a contract document, or as a deliverable to the owner. The overall goal of the BIM checklist is to help the project team get to a consensus of the model and how it will help carry the project forward.

Shown below is an expanded version of what is covered in the checklist. This checklist can be further formatted to help mitigate repetitive questions asked in the form when they might not apply to the group that is filling it out. I.e. if the option is to not use

${ }^{69}$ Ibid. 
the Conceptualization section of the form, the rest of that section would be eliminated and move on to the next section. 


\section{BIM Project Checklist}

\section{GENERAL}

The overall goal of the BIM checklist is to help the project team get to a consensus of the model and how it will help carry the project forward.

A List Team Members in Integrated Project, and their role:

B Will be preparing Modeling Matrix

C Will be preparing Project Execution Plan flowchart (PxP)

D List some common goals that the team has for accomplishing and gaining value from model:

Note: Some decisions may accrue extra costs for the project. This should be discussed when filling out checklist.

\section{CONCEPTUALIZATION DESIGN}

Conceptualization Design: where a project team (Owner, Design Team, Constructor) involved in the project provide input for the design of the project. This stage is where performance goals, preliminary schedule, and cost estimate are established.

BIM is/is not used for this phase of the project:

$\begin{array}{ll} & \text { Not } \\ \text { Used } \quad \square \quad \text { Used }\end{array}$




\section{A MASSING MODEL}

Is a Conceptualization model required for the contract?

$\mathrm{Y}$ This is a massing model and will be fully developed into final model used for the project.

Contract includes this as a line item that required to be done during contract duration.

Submit this iteration at the end of the project to show development.

$\mathrm{N}$ This is a supporting document that is used for the team's design development, not required by the contract.

Breakdown Structure (create zones, floor, phases of building(s) being built, major systems included)

Modeling program(s) used:

Who has the ability to change or edit model?

Y N Can be edited during scheduled meetings.

If no, list when it is acceptable to make changes:

\section{B SCHEDULE}

Is a Conceptualization Design schedule required for the contract?

Y Schedule will be used to further develop the model during Conceptual Design phase.

Contract includes this as a line item that required to be done during contract duration.

Submit this iteration at the end of the project to show development.

List major milestones to be included in Conceptualization Design schedule:

Program(s) used to connect to

BIM:

N Conceptual Design schedule is not needed.

A Conceptualization Design schedule will not be developed in this phase.

A Conceptualization Design schedule is not required by the contract, but will be used to further develop the schedule 
attached to the model.

List major milestones to be included in Conceptualization Design schedule:

\section{ESTIMATE}

Is a Conceptualization Design estimate required for the contract?

Y Estimate will be used to further develop the model during Conceptual Design phase.

Contract includes this as a line item that required to be done during contract duration.

Submit this iteration at the end of the project to show development.

List major cost allowances to be included in Conceptualization Design estimate:

Program(s) used to connect to

BIM:

N Conceptual Design estimate is not needed.

A Conceptualization Design estimate will not be developed in this phase.

A Conceptualization Design estimate is not required by the contract, but will be used to further develop the schedule attached to the model.

List major cost allowances to be included in Conceptualization Design estimate:

\section{CRITERIA DESIGN}

Criteria Design: Where ideas are implemented and evaluated by the team to satisfy project parameters.

BIM is/is not used for this phase of the project:

$$
\text { Not }
$$

Used $\quad \square$ Used

A $\quad \square \quad$ Used Conceptual Design phase.

What was used from conceptualization design phase: model, schedule, estimate? 


\section{B CRITERIA MODEL}

Is a Criteria model required for the contract?

$\mathrm{Y}$ This is an iterative model and will be fully developed into final model used for the project.

Contract includes this as a line item that required to be done during contract duration.

Submit this iteration at the end of the project to show development.

$\mathrm{N}$ This is a supporting document that is used for the team's iteration development, not required by the contract.

If there are multiple models being developed to pin down design, list differentiating characteristics:

Breakdown Structure (create zones, floor, phases of building(s) being built, major systems included)

Modeling program(s) used:

Who has the ability to change or edit model?

Y N Can be edited during scheduled meetings. If no, list when it is acceptable to make changes:

\section{SCHEDULE}

Is a Criteria Design schedule required for the contract?

Y Schedule will be used to further develop the model during Criteria Design phase.

Contract includes this as a line item that required to be done during contract duration.

Submit this iteration at the end of the project to show development.

List major milestones to be included in Criteria Design schedule:

Program(s) used to connect to

BIM:

N Criteria Design schedule is not needed.

A Criteria Design schedule will not be developed in this phase. 
A Criteria Design schedule is not required by the contract, but will be used to further develop the schedule attached to the model.

List major milestones to be included in Criteria Design schedule:

Will the schedule be connected to a time lapse with the model?

\section{ESTIMATE}

Is a Criteria Design estimate required for the contract?

Y Estimate will be used to further develop the model during Conceptual Design phase.

Contract includes this as a line item that required to be done during contract duration.

Submit this iteration at the end of the project to show development.

List major cost allowances to be included in Conceptual Design estimate:

\section{Program(s) used to connect to}

BIM:

N Criteria Design estimate is not needed.

A Criteria Design estimate will not be developed in this phase. A Criteria Design estimate is not required by the contract, but will be used to further develop the schedule attached to the model.

List major cost allowances to be included in Criteria Design estimate:

\section{E LIFECYCLE \& SUSTAINABILITY}

Modeling program(s) used:

What lifecycle and sustainability studies are being done? (light, solar, lifecycle, etc.)

Conducting study for sustainable credit/award.

Who is in charge of model and studies?

Time Period that testing will run: 


\section{DETAILED DESIGN}

Detailed Design: All major building systems are to be fully designed, the Design Documents (DDs). Subcontractors may be introduced to give input for system coordination.

BIM is/is not used for this phase of the project:

\section{Not}

Used $\quad \square$ Used

A $\square \quad$ Used Conceptual Design phase.

What was used from conceptualization design phase: model, schedule, estimate?

Used Criteria Design phase.

What was used from Criteria Design phase: model(s), schedule, estimate?

\section{B DETAILED DESIGN MODEL}

Is a Detailed Design model required for the contract?

$\mathrm{Y}$ This is a final working model, and the design will be complete in this model.

Contract includes this as a line item that required to be done during contract duration.

Submit this model at the end of the project as closeout documents.

Convert 3D drawings into 2D plans for field use.

$\mathrm{N}$ This is a supporting document that is used for the team's understanding, not required by the contract.

Use document to implement clash detection/prevention into the project.

Breakdown Structure (create zones, floor, phases of building(s) being built, major systems included)

Model is used for site layout and coordination.

Modeling program(s) used:

Who has the ability to change or edit model?

$\mathrm{Y} \quad \mathrm{N} \quad$ Can be edited during scheduled meetings.

If no, list when it is acceptable to make changes: 


\section{SCHEDULE}

Is a Detailed Design schedule required for the contract?

Y Schedule will be used to further develop the model during Detailed Design phase.

Contract includes this as a line item that required to be done during contract duration.

Submit this iteration at the end of the project to show development.

List major milestones and determine critical path to be included in Detailed Design schedule:

Program(s) used to connect to

BIM:

N Criteria Design schedule is not needed.

A Detailed Design schedule will not be developed in this phase.

A Detailed Design schedule is not required by the contract, but will be used to further develop the schedule attached to the model.

List major milestones to be included in Detailed Design schedule:

Will the schedule be connected to a time lapse with the model?

\section{ESTIMATE}

Is a Detailed Design estimate required for the contract?

Y Estimate will be used to further develop the model during Detailed Design phase.

Contract includes this as a line item that required to be done during contract duration.

Submit this iteration at the end of the project to show development.

List major cost allowances to be included in Detailed Design estimate:

Program(s) used to connect to

BIM:

N Criteria Design estimate is not needed.

A Detailed Design estimate will not be developed in this 
phase.

A Detailed Design estimate is not required by the contract, but will be used to further develop the schedule attached to the model.

List major cost allowances to be included in Detailed Design estimate:

\section{E LIFECYCLE \& SUSTAINABILITY}

Modeling program(s) used:

What lifecycle and sustainability studies are being done? (light, solar, lifecycle, etc.)

Conducting study for sustainable credit/award.

Who is in charge of model and studies?

Time Period that testing will run:

\section{IMPLEMENTATION DOCUMENTS}

Implementation Documents: to consist of the compilation of documents to move forward with building, the Construction Documents Phase (CDs)

BIM is/is not used for this phase of the project:

Not

Used $\quad \square \quad$ Used

\section{A DETAILED DESIGN MODEL LOD}

Is a Detailed Design model required for the contract?

$\mathrm{Y}$ This is a final working model, and the design will be complete in this model.

Contract includes this as a line item that required to be done during contract duration.

Submit this model at the end of the project as closeout documents.

$\square$ Convert 3D drawings into 2D plans for field use.

$\mathrm{N}$ This is a supporting document that is used for the team's understanding, not required by the contract.

Use document to implement clash detection/prevention into the project.

Breakdown Structure (create zones, floor, phases of building(s) being built, major systems included) 
Model is used for site layout and coordination.

Modeling program(s) used:

Who has the ability to change or edit model?

Y N Can be edited during scheduled meetings.

If no, list when it is acceptable to make changes:

\section{B SCHEDULE}

Is a Detailed Design schedule required for the contract?

Y Schedule will be used to further develop the model during Detailed Design phase.

Contract includes this as a line item that required to be done during contract duration.

Submit this iteration at the end of the project to show development.

List major milestones and determine critical path to be included in Detailed Design schedule:

Program(s) used to connect to

BIM:

N Criteria Design schedule is not needed.

A Detailed Design schedule will not be developed in this phase.

A Detailed Design schedule is not required by the contract, but will be used to further develop the schedule attached to the model.

List major milestones to be included in Detailed Design schedule:

Will the schedule be connected to a time lapse with the model?

\section{ESTIMATE}

Is a Detailed Design estimate required for the contract?

Y Estimate will be used to further develop the model during Detailed Design phase.

Contract includes this as a line item that is required to be done during contract duration. 
Submit this iteration at the end of the project to show development.

List major cost allowances to be included in Detailed Design estimate:

Program(s) used to connect to

BIM:

N Criteria Design estimate is not needed.

A Detailed Design estimate will not be developed in this phase.

A Detailed Design estimate is not required by the contract, but will be used to further develop the schedule attached to the model.

List major cost allowances to be included in Detailed Design estimate:

\section{AGENCY COORDINATION}

Agency Review: Permitting and design review phase.

BIM is/is not used for this phase of the project:

$$
\text { Not }
$$

Used

Used

Note that extensive coordination between all trades prior to submittal reviews of documents for model to have been developed. Agency review can begin as early as Criteria Phase.

A Which Phase did Agency Review begin?

Criteria Design

Detailed Design

Implementation Documents

B Deliverable Type

Traditional Deliverable

Digital Deliverable

\section{CONSTRUCTION}

Construction: Quality control and cost monitoring.

BIM is/is not used for this phase of the project: 
Not
Used $\quad \square \quad$ Used

A $\quad \square \quad$ Used Conceptual Design phase.

Y Check phases used below and explain LOD.

What was used from conceptualization design phase: model, schedule, estimate?

First model to be created in the project

$\mathrm{N}$ Will be creating model specifically for this phase.

Working with subcontractors to produce model. List trades to be included in model below.

Used for prefabrication. List trades and major systems that will be utilizing prefabrication from the model.

B $\square \quad$ Is a Construction model required for the contract?

$\mathrm{Y}$ This is a final working model?

Contract includes this as a line item that required to be done during contract duration.

Submit this model at the end of the project for closeout documents.

Convert 3D drawings into 2D plans for field use.

$\mathrm{N}$ This is a supporting document that is used for the team's understanding, not required by the contract.

Use document to implement clash detection/prevention into the project.

Breakdown Structure (create zones, floor, phases of building(s) being built, major systems included)

Model is used for site layout and coordination.

Modeling program(s) used:

Who has the ability to change or edit model?

Y N Can be edited during scheduled meetings.

If no, list when it is acceptable to make changes:

Model was used for exploration of existing conditions?

Y Model was used

A model already existed for previous site or surrounding areas. 


\section{LOD:}

Model was prepared based on plans that existed. List what model will include.

\section{SCHEDULE}

Is a Construction schedule tied to the model required for the contract?

Y Schedule will be used to further develop the model during Construction phase.

Contract includes this as a line item that required to be done during contract duration.

Submit this iteration at the end of the project to show development.

List major milestones and determine critical path to be included in Construction phase schedule:

Program(s) used to connect to

BIM:

$\mathrm{N}$ Construction schedule tied to the model is not required for the contract?

A Construction phase schedule tied to model will not be developed in this phase.

A Construction phase schedule tied to model is not required by the contract, but will be used to further develop the schedule attached to the model.

List major milestones to be included in Construction phase schedule tied to model:

Will the schedule be connected to a time lapse with the model? It will show:

Milestones

Activity

Zones

Other:

Schedule will only be tied to specific activities in the model. List below.

\section{E LIFECYCLE \& SUSTAINABILITY}


Modeling program(s) used:

What lifecycle and sustainability studies are being done? (light, solar, lifecycle, etc.)

Conducting study for sustainable credit/award.

Who is in charge of model and studies?

Time Period that testing will run:

\section{CLOSEOUT/ POST CONSTRUCTION}

Closeout/Post Construction: Compilation of record drawings.

BIM is/is not used for this phase of the project:

Not

Used $\quad \square$ Used

\section{A CLOSEOUT DOCUMENTATION}

$\mathrm{Y}$ This is a final working model?

Contract includes this as a line item that required to be done during contract duration.

Model will updated for closeout documentation.

Convert 3D drawings into 2D plans for final submission.

Contractors will be providing final models for document submittal.

Contractors will provide Designers with models to be implemented in final document submittal.

Modeling program(s) used:

$\mathrm{N}$ This is a supporting document that is used for the team's understanding, not required by the contract.

B FACILITIES MANAGEMENT

Y Model will be used for Facilities Management of the building.

What system(s) or program(s) is

the model tied to?

What do the programs track? 
Level of Detail required of model to run system(s)/program(s): Who conducts Facilities

Management? Owner Build Other:

N Model will not be used for Facilities Management of the building.

\section{LIFECYCLE \& SUSTAINABILITY}

Y Model will be used for Post Occupancy Studies of the building. What sustainable element(s) are being tracked?

Conducting study for sustainable credit/award.

$\square \quad$ Modeling program(s) used:

What system(s) or program(s) is the model tied to?

What do the programs track?

Level of Detail required of model to run system(s)/program(s):

N Model will not be used for Post Occupancy Studies of the building. 


\section{CHAPTER 7}

\section{CONCLUSION}

\subsection{Overview}

This study was intended to explore the concept of BIM utilization in an Integrated Project: when it should be implemented, its reasons for being used, the level of detail that was implemented, and how the level of use was decided. The analysis also sought the impact of BIM on the project, and whether it hindered or helped with a successful delivery. The study sought to answer the question of how extensive the BIM process should be and when should it be implemented on an IPD building project.

\subsection{Case Studies}

The main empirical findings are found in Chapter 4, Case Studies. How extensive should the BIM process be and when should it be implemented on an IPD building project?

a. Both projects were required by the Owners to utilize BIM for the duration of the project.

b. BIM guidelines were set and sometimes tailored to fit the project needs. In some instances, an element of BIM was implemented just to fulfill the quota of being used, while other times it was used more extensively than required.

c. Both projects showed a successful delivery by implementing BIM elements early within the building process.

\subsection{Theoretical Implication}

The implications of this paper have found that BIM needs to be part of the contract. The team consensus of BIM usage opens up a conversation to establish what will be included in the contract. With the team agreeing that BIM should be included, the 
discussion of how it should be implemented can increase understanding for all parties. When the major parties understand what will be included in the contract, it is easier to enforce and implement the BIM practices for the duration of the project.

\subsection{Contract Implication}

Specific contract language for BIM, rather than singular line items, will help illustrate the integration of BIM in the various segments of the project. Increased development of this language works to specific the use of BIM within contracts. Contracts could then act as stricter guidelines for LOD and dimensions of BIM used. These guidelines can be tailored to the different phases of the project, creating a comprehensive understanding of BIM usage for all parties.

\subsection{Recommendation for Future Research}

This analysis has given a sampling of two projects that used an Integrated Project method, both using BIM extensively. To gain more insight on the application of BIM within a project, there is a need for more case studies to allow for further assessment of when BIM has been used and further strategies on when it should be implemented per project basis.

An ultimate goal is to develop the checklist further into a contract document. As mentioned earlier in the thesis, the checklist is not currently comprised of legal language. This presents an opportunity to further develop the document for the three parties to use in discussion settings and for use as the basis of BIM documentation in a IPD project.

\subsection{Limitation of Study}

Other elements may need to be considered: a project's success without the use of BIM throughout the project, BIM used in the project by only one party, or the use of BIM 
in another project delivery method. It is difficult to contact a project team after the project is complete, and it would be better to conduct interviews during the closeout of the project.

\subsection{Closing Comments}

BIM is still in development stages, and the building industry continues to shape itself as the need for the technology grows. BIM has shown success in projects, but there are some instances where BIM needs help to grow and be established, especially when BIM usage is beneficial. 


\section{BIBLIOGRAPHY}

“Better Designs. Smarter Operations.” Autodesk, 2010. Accessed May 15, 2015. http://static-dc.autodesk.net/content/dam/autodesk/www/industries/architectureengineering-construction/building-owner-operations-management/Docs/usc-v7.pdf.

Bedrick, Jim. "Organizing the Development of a Building Information Model." American Institute of Architects, 2008. Accessed June 15, 2015. http://www.aia.org/groups/aia/documents/pdf/aiab078868.pdf.

Bhari, Mandeep. "USC Cinematic Arts Project." Telephone interview by author. January 7, 2014.

Boton, Conrad, Sylvain Kubicki, and Gilles Halin. "Designing Adapted Visualization for Collaborative 4D Applications." Automation in Construction, 2013, 152-67. Accessed January 28, 2015.

Brenden Bradley and Gregory Gangitano (Parnters at Gordon \& Rees LLP Construction Group Associates) in discussion with the author, March 2015

Bryson, Barbara White, and Canan Yetmen. The Owner's Dilemma: Driving Successs [i.e. Success] and Innovation in the Design and Construction Industry. Atlanta, GA: Östberg Library of Design Management, Greenway Communications, 2010.

"Civil Code Section 1619-1633." CA Codes (civ:). Accessed July 8, 2015. http://www.leginfo.ca.gov/cgi-bin/displaycode?section=civ\&group=01001$\underline{02000 \& \text { file }=1619-1633}$.

"Cinematic Arts Complex." USC School of Cinematic Arts. Accessed May 2, 2015. http://cinema.usc.edu/facilities/complex.cfm.

Consensus Docs Guidebook. 2015. 2300 Wilson Blvd., Suite 300, Arlington, VA. Accessed March 15, 2016. http://www.consensusdocs.org/Resource_FileManager/All_Associations_Guidebook .pdf.

"Contract Documents." About Contract Documents. Accessed March 15, 2016. http://www.aia.org/contractdocs/about/index.htm.

"Contract Documents." AIA RSS. Accessed July 2015. http://www.aia.org/contractdocs/AIAS076721.

"Contract Catalog." Contract Catalog. Accessed March 15, 2016. https://www.consensusdocs.org/catalog/collaborative.

Dossick, Carrie Sturts, and Gina Neff. "Messy Talk and Clean Technology: Communication, Problem-solving and Collaboration Using Building Information Modelling." Engineering Project Organization Journal, 2011, 83-93. Accessed January 28, 2015. 
Deutsch, Randy. BIM and Integrated Design Strategies for Architectural Practice. Hoboken, N.J.: Wiley, 2011. Accessed January 27, 2015. ProQuest ebrary.

Eastman, Charles M. "The Use of Computers Instead of Drawings in Building Design." AIA Journal 63, no. 3 (1975): 46-50.

Epstein, Erika. Implementing Successful Building Information Modeling. Boston, MA: Artech House, 2012.

Forbes, Lincoln H., and Syed M. Ahmed. "Information and Communication Technology/Building Information Modeling." In Modern Construction Lean Project Delivery and Integrated Practices. Boca Raton, FL: CRC Press, 2011, 8-9.

Foster, Rob. Contract Documents. Presentation, San Diego International Airport, San Diego. 2014.

Foster, Rob. Applying BIM to Large Public Construction Programs/Projects. Presentation, San Diego International Airport, San Diego. 2013.

Foster, Rob. Transportation and Utility Projects Case Studies Using BIM. Presentation, San Diego International Airport, San Diego. 2013.

"Integrated Project Delivery - A Working Definition." American Institute of America California Council, 2007. Accessed June 15, 2015. https://www.dir.ca.gov/das/hcc/WorkingDefinition.pdf.

"Integrated Project Delivery: A Guide." American Institute of Architects, 2007. Accessed June 07, 2015. http://www.aia.org/groups/aia/documents/pdf/aiab083423.pdf.

Jackson, Barbara J. Design-build: Design-build Essentials. 1st ed. Clifton Park, N.Y.: Delmar/Cengage, 2011.

Jesus Fuentes (USC Cinematic Arts Project Manager). Telephone interview by author. December 2, 2014.

Kensek, Karen M. Building Information Modeling. London: Routledge, 2014.

Kymmell, Willem. Building Information Modeling Planning and Managing Construction Projects with 4D CAD and Simulations. New York: McGraw-Hill, 2008.

Lowe, Richard H., and Jason M. Muncey. "ConsensusDOCS 301 BIM Addendum." Contract Forms and Drafting/Building Information Modeling. 29, no. 1 (2009). Accessed May 2015. https://www.consensusdocs.org/News/Download/d2458cb35ba4-4e2d-bb1d-9fb400cfd2fc?name=ABA-Winter-09-ConsensusDOCS-301-BIMAddendum-Lowe-and-Muncey.pdf.

Mincks, William, and Hal Johnston. "Use of Construction Documents on the Jobsite." In Construction Jobsite Management, 45. 3rd ed. Cengage Learning, 2010. 
"Pedestrian Bridge Placement Takes Many Months, Plus a Single Night | Sundt." Sundt. Accessed June 04, 2015. http://www.sundt.com/media/blog/2012/05/30/1811/.

Popov, Vladimir, Virgaudas Juocevicius, Darius Migilinskas, Leonas Ustinovichius, and Saulius Mikalauskas. "The Use of a Virtual Building Design and Construction Model for Developing an Effective Project Concept in 5D Environment." Automation in Construction, 2009, 357-67.

"Projects." USC School of Cinematic Arts Phase III. Accessed July 07, 2015. http://www.mattconstruction.com/project-detail/bim-projects/usc-school-ofcinematic-arts-phase-iii.

Reddy, K. Pramod. BIM for Building Owners and Developers : Making a Business Case for Using BIM on Projects. Hoboken, NJ, USA: John Wiley \& Sons, 2011. Accessed January 27, 2015. ProQuest ebrary.

Rob Foster (Project BIM Manager) in discussion with the author, March 2015.

"San Diego International Airport Terminal 2 Landside Expansion | Sundt." Sundt. 2014. Accessed July 1, 2015. http://www.sundt.com/projects/san-diego-internationalairport-landside-package-int-jv-so-cal-share/.

Stein, Steven G.M., and Ronald O. Wietecha. Who's Ox Is Being Gored?: A Comparison of ConsensusDOCS and AIA Form Construction Contract Agreements. Stein, Ray \& Harris, LLP. 2008. Accessed February 7, 2016.

Sweet, Justin, and Marc M. Schneier. "Contracts: From Formation to Breach." In Legal Aspects of Architecture, Engineering and the Construction Process, 43-44. 9th ed. Stamford, Conn.: Cengage Learning, 2013.

"The Green Build." San Diego International Airport Airport Projects. Accessed July 1, 2015. http://www.san.org/Airport-Projects/The-Green-Build.

University of Southern California [map]. 2015. Scale undetermined; generated by Google; using "Google.com, Inc." https://www.google.com/maps/place/University+of+Southern+California/@34.0223 $\underline{563,-}$ 118.2873111,17z/data=!3m1!4b1!4m2!3m1!1s0x80c2c7e49c71a5ed:0xaa905a5bb42 $\underline{7 a 2 c 4 ? h l=e n}$.

Weygant, Robert S.. BIM Content Development: Standards, Strategies and Best Practices. Hoboken, NJ, USA: Wiley, 2011. Accessed January 27, 2015. ProQuest ebrary.

US Army Corps of Engineers. USACE BIM Project Execution Plan Version 2.1.

US Army Corps of Engineers. USACE M3 Template.

US Army Corps of Engineers. USACE PXP Template. 
Yalcinkaya, Mehmet, and David Arditi. "Building Information Modeling (BIM) and the Construction Management Body of Knowledge." In Product Lifecycle Management for Society: 10th IFIP WG 5.1 International Conference, PLM 2013, Nantes, France, July 6-10, 2013: Proceedings, compiled by Alain Bernard, Louis Rivest, and D. Dutta, 619-29. Vol. 409. IFIP Advances in Information and Communication Technology. Springer Berlin Heidelberg, 2013. 
APPENDICES 
Appendix A:Acronyms

\begin{tabular}{|c|c|}
\hline AGC & Associated General Contractors \\
\hline AIA & American Institute of America \\
\hline BIM & Building Information Modeling \\
\hline CAD & Computer Aided Drafting \\
\hline $\mathrm{CM}$ & Construction Manager \\
\hline CMAR & CM at Risk \\
\hline COBie & Construction Operations Building Information Exchange \\
\hline $2 \mathrm{D}$ & 2 Dimensional \\
\hline $3 \mathrm{D}$ & 3 Dimension Dimensional \\
\hline 4D & 4 Dimension Dimensional \\
\hline $5 \mathrm{D}$ & 5 Dimension Dimensional \\
\hline $6 \mathrm{D}$ & 6 Dimension Dimensional \\
\hline $7 \mathrm{D}$ & 7 Dimension Dimensional \\
\hline DB & Design-Build \\
\hline FM & Facilities Management \\
\hline GC & General Contractor \\
\hline IDP & Integrated Project Delivery \\
\hline JV & Joint Venture \\
\hline LEED & Leadership in Energy and Environmental Design \\
\hline LOD & Level of Detail/Level of Development \\
\hline M3 & Minimum Modeling Matrix \\
\hline NBIMS & National BIM Standards \\
\hline $\mathrm{OAC}$ & Owner Architect Contractor \\
\hline PxP & Execution Plan \\
\hline $\mathrm{QA} / \mathrm{QC}$ & Quality Assurance/ Quality Control \\
\hline QBS & Qualification Based Selection \\
\hline RFP & Request for Proposal \\
\hline USACE & US Army Corp of Engineers \\
\hline VD\&C & Virtual Design and Construction \\
\hline
\end{tabular}

